\title{
Education to Theatricality: The Theatrical Workshop as a Training Model the Expressive and Performing Arts in Education
}

\author{
Gaetano Oliva ${ }^{1, *}$ \\ ${ }^{1}$ Faculty of Education, Italian department, Catholic University, Milan, Italy \\ *Correspondence: Università Cattolica del Sacro Cuore di Milano, Facoltà di Scienze della Formazione, \\ Dipartimento di Italianistica e Comparatistica, Largo Gemelli, 1, 20123 Milano, Italy. E-mail: \\ gaetano.oliva@unicatt.it
}

Received: January 7, 2015

Accepted: April 2, $2015 \quad$ Online Published: April 10, 2015

doi:10.5430/wje.v5n2p86

URL: http://dx.doi.org/10.5430/wje.v5n2p86

\begin{abstract}
Background: Education to Theatricality as pedagogical and artistic research is experienced by almost twenty years in Italy in laboratories and projects organized in collaboration with universities, schools, theaters, educational centers, cultural centers, educational and social services, associations. Education to Theatricality is a science that includes different of disciplines such as pedagogy, sociology, human sciences, psychology and the performing arts in general. The scientific basis of this discipline allows us to apply it in all possible contexts possible and with any individual, because it keep the man as he is in the center of its pedagogical process. One of the fundamental principles of Education to Theatricality is the construction of the actor - person; the main aim is the development of creativity and imagination through a scientific training leads by the actor on himself. The present theoretical writing synthetically introduces the fundamental elements of the theory.

Method: This study discusses relationship between theater and education analyzing the main elements of this meeting.

First part presents the theories: the birth of the theatrical workshop, development of Education to Theatricality and the definition of its theoretical issues: I-AM's scheme; creative subject, creative act; laboratory and its aesthetic philosophy: Art as a vehicle. Second part presents theater pedagogy through creative movement. The text presents the exercises on the languages of human communication the method of work. Third part presents projects and planning in education laboratory expressive arts.

Conclusions: Education to Theatricality as pedagogy uses the expressive arts into the theatre workshop for to lead the subject to path of growth and training activating the original potential skills of this person.
\end{abstract}

Keywords: innovative pedagogical models; art education; aesthetic education; early childhood education; special education; theatre education

\section{First Part: Theory. Theater and Education}

Art forms like music, dance, theater, painting, visual and plastics arts representative expressions of a humanity that, since the dawn of its history, trying to get in touch with her inner self.

Why we can speak about the relationship between the theater and the education? We can answer only if we consider the needs of the twenty-first century. Today theatre can be defined only taking accounts of educative contexts. In fact, this is the new theatre frontier, from the point of view of the actor, of the scene, of the dramaturgy. Afterwards great avant-gardes, research, years characterized by tendencies and oppositions, we need a theatre that considers pedagogy and that shows itself as a mental and physic place where both, human and actor, can regain their forces. This change is rich of anthropological implications; in fact it has created an ideal place where the masters of twentieth century can interact, joining or breaking away, stimulating the reproduction of their thoughts. The theatre, now, accepts itself as an ancient and primal art that lives on in the present. It is living a sort of unexpected youth and it seems to be outside the contemporary world, which is characterized by a returning oldness in a lot of different areas. In its history, theatre has often been the copy of the social system and of the anthropological type. If we compare the present theatre to the historical traditions, we can see that it is ready to perform particular functions which are original and primal. It unites the dramatic objectivity of events to the lyrics contents of the actor; it transforms the 
social-educative dynamics into scenic forms; it reclaims the narration, which comes from its own physiology and not from the narrative traditions. It assimilates the past to its relational system.

The present situation is still now uncertain, maybe because it is inhibited by the great twentieth century theatre examples. The present theatre is far from the historical dynamics between traditional and new, ancient and modern, and it is characterized by two fields of research. The first one considers theatre as something to rebuild and discover, something which can realize new structures, new art forms and new way to create relationship between actors and audience outside the institutional places, for example in the educative world. The second one is about dramaturgy. It is he time to pass over the theatrical text and to look for a new kind of writing. It should be more creative, come out directly from the stage and it should pay more attention to the needs of the context. Then, this dramaturgy can be considered a new writing because it is created just by the new generations that are involved in the present educative world. Here it is the reason of our choice to study the relationships between the theater and the education inside a theoretical framework in contemporary scientific research: Education to Theatricality.

\subsection{Thoughts and Utopia: The Theatre of the Twenty-First Century}

New esthetic researches come from the concept of art as vehicle. The twenty-first century theatre is characterized by a lot of particular events, for example the idea of theater as vehicle (by Grotowski) and, consequently, the birth of Education to Theatricality. This is an element that testimony how much the theatrical art is changing during this new century.

\subsection{The Birth of Education to Theatricality}

New esthetic researches come from the concept of art as vehicle. These researches want to create, through the theatre, a relationship with humans that must have a value and a sense, until reaching a society that needs theatre. This concept comes from the reflections of Appia and Craig, who have thought over the scenography, of Stanislavskij, Vachtangov, Mejerchol'd, Copeau, Chancerel who were interested in the actor's point of view, of Brecht, a dramatist, and of many others. The new theatre wants to regain a human, social and cultural complexity of art, seen as expressive communication and human realization (Oliva, 2011: pp. 72-82).

This theatre is composed of two dimensions: it is focused on the human training and, consequently, of the actor. It has also the aim to break down the barriers between the stage and the viewers. The actor is the center of the researches of the twenty first century: his expressive dimension of making theatre, his relationship with the audience and with other actors. This is an actor who uses himself consciously to express something.

At the beginning of twenty-first century, the actors who wanted to join in the local company often decided to attend a theatre school. In fact, a lot of the greater theatres have an own school, like for example the Art Theatre of Moscow.

These schools were linked to a particular teacher, but they have not either method, or theoretic basis or a pedagogical plan. Their purpose was to break in the future actors to mount shows in a very short time. Nevertheless in this theatre Konstantin Sergeevic Aleksèev Stanislavskij revolutionized the "theatrical technics" opposing to that idea of actors' training. He started from his experience as actor and he inserted a method of experimental research on the actor, developing some ideas of Appia and Craig, his predecessors. The Stanislavskij System is not just a theory, it is a pedagogical praxis, and it is transmission of an experience through the action. According to Stanislavskij's idea, an actor has to learn, in order to train new actors. He has to be able to show the research path, that must be personalized by who wants to undertake the long process of self-awareness. If somebody saw Stanislavskij's actors from a distance, he could think that they owned mysterious secrets and particular instruments. In reality they were just men, characterized by a great morality and who have experienced a particular kind of training, which had changed them. Grotowski passed over Stanislavskij's concepts, and he underlined the importance of the person's training respect the theatrical product, even if this one has to have an esthetic form because it permit the communication between the actor and the audience.

The meeting between the dramatic art and pedagogy, for the first time in history, is one of the factors that have influenced the changing of the theatre during the twentieth century (after Grotowski). Theatre and pedagogy have discovered to have the same purposes and the same interests: the theatre allows human to emphasize his expressive skills and to show hid creativity and imagination. The attention moves from the performance (which was considered the final purpose of the dramatic experience) to the actor as the real protagonist of this dramatic renewal.

The Education to Theatricality and the laboratory method, the studies, the schools of the great pedagogues of the twentieth century, the concept of the theatrical laboratory by Grotowski, are an occasion for actors to express themselves freely. The theatre laboratory is called Studio by Stanislavskij, Grotowski and Education to Theatricality and it is born to find a solution for professional problems. Now, the laboratory is the center of the new theatre 
pedagogy, which considers the exercises as an active part of the theatre and not only something useful to mount shows. The exercises are an important part of the actor's training, of the "trenàz" as Mejerchol'd says; they are essential for the performance, but they are not a part of it. During the Studio time, each actor tries to find expressive e possibilities with body and voice. So, he can have a lot of chances of expression that he can use in the course of the performance. If we analyze the pedagogical work of the laboratory, we can notice that it is strictly linked to a process stimulated by the pedagogues-director who holds it. The director spurs up actors that can have always new experience thanks to exercises and improvisations. This technics are the most important part of the whole work; they represent the creative process phase, when actors are looking for what they do not know; they are useful to replace creativity to repetition and to create an own tradition. At the end of the process, the actor has to think over his work, to understand what he has lived and how he has improved his awareness.

The laboratory is born just for theatre, but then it is become a useful educative instrument, above all thanks to Grotowski's theories. In fact it is a well delimitated period of time and a protected place. Moreover, it has the same educative aims of the most important pedagogues of the last two century, as Froebel, Dewey, Montessori, Ferrière, Claparède, who thought that experience has a training value for the students. In the Laboratory, the master-group leader does not teach, he offers his own technic and professional skills. The students, if they are conveniently led, can face an individual process and through it they can listen to themselves and discover their limits and their skills. They learn new abilities, useful to express their thought and their feelings. In the Education to Theatricality the laboratory is a physic and a mental place where the pupil can develop a work useful to his growth, it is a chance to learn by doing, with the belief that the most important aspect of the laboratory is the process and not the end. In order to better understand the changes of the theatre over the last years, it is better to consider its single elements instead of to think it as a great united art, and these elements can be considered humble "trades".

\subsection{Education to Theatricality": A Science}

"Education to Theatricality" has a lot of purposes to contribute to the psycho-physic well-being of each person; particularly it wants to help everyone to realize himself, as human being and as social actor; it wants to give everybody the chance to reveal his own diversity and specificity, because everybody has a message to convey through his body and his voice (Oliva, 2014: pp. 1758-1775). The "Education to Theatricality" wants to stimulate skills, it wants to develop a better awareness of interpersonal relationships; it wants also give space to the assignment meaning process, because it considers "doing" as important as thinking, that permit to develop awareness about personal acts. Over the past few years, pedagogy, inspired from psychology, medicine and existential philosophy, has corrected his intellectualism and started to underline the importance to have a vision of the whole human being, who is composed by different components. At the same time, it emphasizes the inventive possibilities of each person. The dramatic expression, as a mean of education, is the perfect answer to this new cultural perspective.

Education to Theatricality cannot be considered part of just one particular artistic discipline, but it must be inserted into a wide-ranging analysis of man and of human being's existence. Movement crosses several disciplines because we start our synthesis from the anthropological concept of art, which does not coincide with the realization of an aesthetic product, but with man's need to manifest and represent himself. Expressive arts become a vehicle through which every man finds and defines his own place in the world. Art is linked to a process, an inner research of meaning carried out by the person; it is tied to the universal Ego of human nature. Dramatic expression, in fact, is a constant call for every kind of language. Spontaneity is not lawlessness or disorder, in fact it is necessary to adapt roles and to build agreements with others to increase our own ego and to tend to a greater awareness.

\subsubsection{Theatricality: Expressive Arts and Pedagogy}

Education to Theatricality reveals many different aims to contribute to the psycho-physical and social wellness of every person; in particular it wants to help each person to realize her or himself as an individual and as a social subject; it wants to give the opportunity to everyone to express their specificity and diversity, as a bearer of a message which should be communicated through body and voice; it wants to stimulate skills; it wants to build a greater awareness of interpersonal relationships; it wants to give space to the process of signification assignment, because it considers action as well as reflection, which allow persons to gain awareness of their actions. Thanks to the laboratory model created and developed by Grotowski, a new form of theatre begins. Its aim is to educate the person. It is a warm and friendly environment in which man is able to enhance his psycho-physical well-being through a process that leads him to experience both his own intimacy and external reality, without fear to be judged, because the starting point is the respect of the experimentation, of creativity and of personality of the other. So, "theater does not promise to transform a man in a super-man, but it can be an excellent test, can give to everyone the measure of his personal nature. So we do not talk about an actor as an abstract entity, but of a "person-actor" [...]" 
(Oliva, 1999: p. 93). Grotowski's Laboratory is based on the concept of person-actor, whose finality is precisely to value and respect personal qualities; the idea of object-actor is denied: the man is no more seen as an object of the market because which is considered only as an executor of an artistic product. The main difference between these two visions is that in the first, the show takes on a value relative to the training process of the performance itself; the product has an importance because it is the fruit of creativity sprung from the relationship of individuals during the laboratory. In the second case, instead, the artistic production has a value in itself and it is the objective to achieve.

The starting point, therefore, is to keep that natural expression that everyone retains within himself; you can define it pre-expressivity, a term that is derived by Eugenio Barba's Theater Anthropology (director and Italian theatre theorist, as well as a student of Grotowski), which "studies the human behavior at a biological and sociocultural level in a situation of representation" (Oliva, 1999: p. 90). In the construction of the person-actor, the purpose is just to develop the person in its organic structure, starting from his or her nature and essence, through a work on the Ego that will allow this person to reach his or her natural, physical, emotional and intellectual pre-expressivity. The spontaneity that man manifests through these components will be addressed towards theatrical methodology so as to develop individual creativity. Man is a relational being, therefore it is necessary that he carries out this individual process within a group. The encounter and the comparison with other people allow him to enter in a dimension of greater understanding of himself and of the others. In fact, thanks to the verbal and nonverbal responses to the behavior of others, the man increases his knowledge and it is placed in a state of discovery. In addition, this situation helps him to be sensitive about the management of space and time. In summary, pupils are accompanied in the conquest of their I-AM. "It was necessary to educate the man and not just the actor, accompanying him to develop a strong self-awareness through a process of discovery and knowledge that began, first of all, from the internal resources of the person. The advice was to always start [...] from themselves to established, with the partner, authentic and sincere relationships" (Oliva, 2005: p. 232). So we confirm, once again, the convergence between art and education: the relational aspect, in fact, turns out to be a key factor both in the educational relationship as in artistic-theatrical relationship. Like education, the theater is a place of encounter: the exchange that takes place between the participants opens the door to so many possibility of discovery. It is not possible, in fact, that an individual may walk on the same path of someone else, because the process in which he is inserted is purely personal because we find ourselves faced to a modality of education that involves the human being in his complexity and in his natural expressiveness.

It is possible to summarize this idea with the Table 1 (Source: Oliva, 1999: p. 98).

Moreover, there is another type of relationship in addition to the relation with our Ego, with a partner and with the context: it is the continuous dialogue that has always to exist between the artistic discipline and other sciences.

In particular, theater has to communicate: with pedagogy, the educational science par excellence that investigates the person as an educable human being and that bases the educational action on relationship; with sociology as a science that studies man in relation to the society in which he is inserted, investigating its influences and characteristics; anthropology, because it is a science that studies the human being in his essence and from different points of view (social, cultural, religious, philosophical, artistic-expressive ); philosophy as science that raises questions about man and reflects about sense of life; aesthetics, field of philosophy that explores the relationship between human being and beauty by an artistic, scientific, moral and spiritual point of view; psychology as a science that studies the behavior of man under the psychic/mental profile and, last but not least, all disciplines of expressive arts. Thanks to this interconnected dialogue, every man is considered in his whole being. 
Table 1. I-AM's Scheme

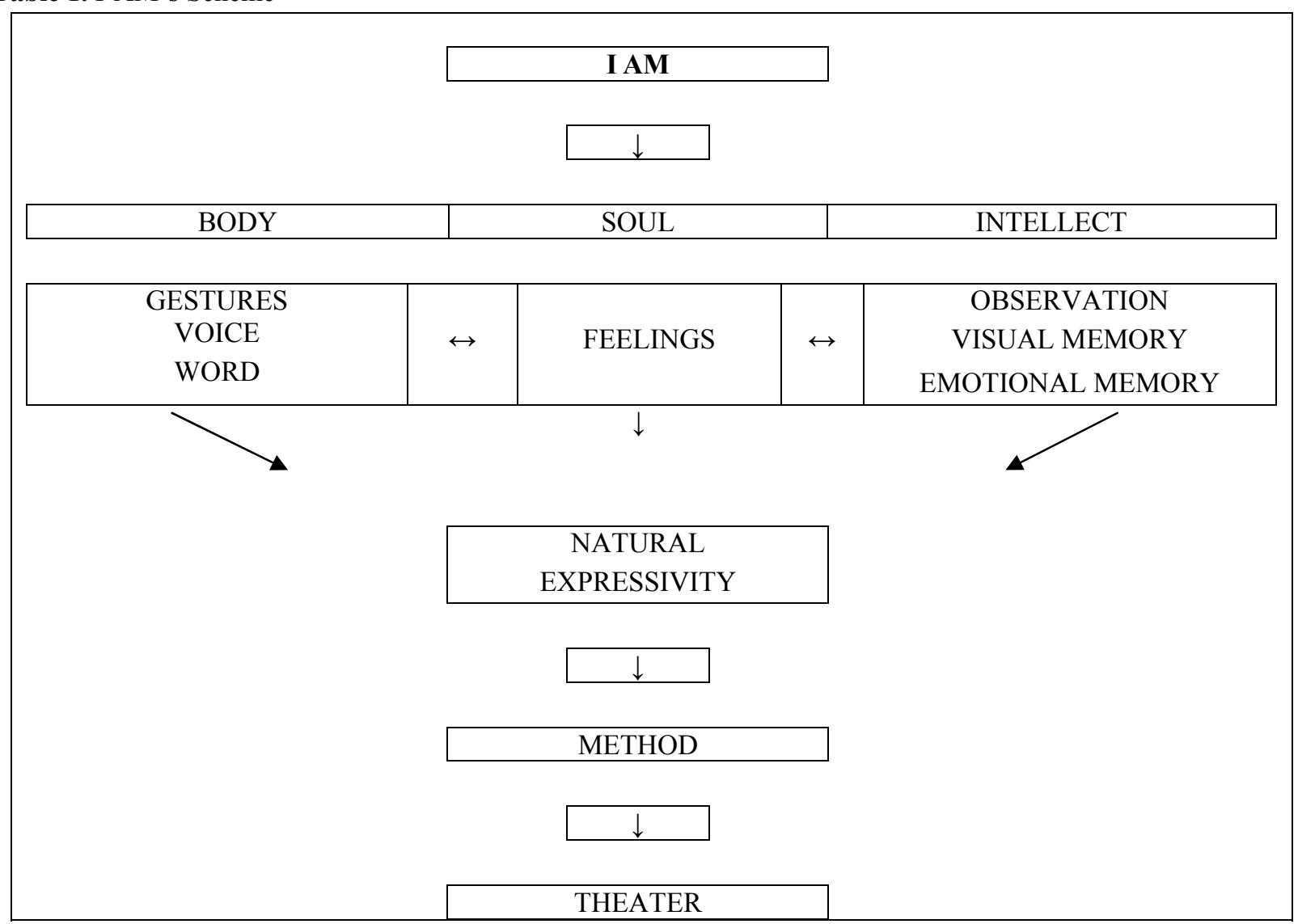

\subsubsection{The Laboratory}

A fundamental aspect of the laboratory of Education to Theatricality is the personal relationship between the participants; a similar relationship should exist between actors and spectators during the creative project that concludes the laboratory itself. The openness to the other is a feature that deeply belongs to man; it is not just a simple exchange of communication, but an experience of affective participation and reciprocity. However, the desire to encounter the other should be real and authentic: this implies that everyone accepts others as they are. The laboratory therefore is an opportunity to grow, to learn by doing, with the belief that the most important thing is the process and not the product: the performance (or creative project) is just the conclusion of a training program. The theatrical activity stimulates the need of an interpersonal knowledge that leads to a relationship in which others are recognized in their dignity. The laboratory offers the opportunity to understand that it is possible to change certain situations and to change ourselves. The laboratory of Education to Theatricality has a great pedagogical value and offers an important contribution to the educational process, because, thanks to the personal training, everyone can learn to express what it is "screaming" inside, to understand and control our energy, to accept what at first was suppressed or repressed. We should not forget that personality of man depends on the quality of his experiences, which characterize his way of relating or not relating, that is his lifestyle. Theater and in particular the laboratory, allows to make new experiences and to experiment different and unusual life situations, which can contribute to redefine the Ego but even the world and the others. Theater means also see again our past: re-experience fears, relive certain behavior - or situations, not to remove them, but to realize that now we are stronger and we can recognize our positivity.

\subsubsection{Aesthetic}

In this context, theater becomes a sort of exercise of beauty, that allows us consider reality in a different and unusual way helping us to find something beautiful everywhere. Interpret reality using the idea of beauty as a key, allow us to abandon the repetitiveness of experience that inhibits every change and helps to understand the complexity of reality which is made of beautiful and ugly things. Theater can therefore be considered as education to beauty, as the 
acquisition of a new instrument of judgment, as an important chance of socialization, as an instrument of change, as a cathartic representation that allows us to think that there is beauty in every human encounter, in every interaction, in any environment.

\subsubsection{Art as a Vehicle}

Education to Theatricality, which find its psycho-pedagogical basis in the concept of art as a vehicle defined by Grotowski, is education for creativity and it represents a precious opportunity for anyone to affirm their identity, claiming the value of the expressive arts as a vehicle for overcoming the differences and as an actual element of integration. Through art, man can tell something about himself, and he is the protagonist of this creation. It puts him in touch with himself, but, at the same time, it creates a connection with the space in a temporal dimension. The Education to Theatricality is a vehicle of growth, of individual development, of self-assertion and of acquisition of new personal skills. The expressive arts do not present models, in fact every man should be each his own model. So, the identity of every person creates a relation through a telling reality; action, word and gesture become instruments of investigation of life. Performance art becomes a vehicle for self-knowledge, for the manifestation of his own creativity.

Art as a vehicle "generates" the idea of an person-actor defined performer, an actual man of action, because he is dancer, musician, actor, total man, which performs a performance, giving completely his personality to the audience. His action does not coy a cliché, it is not a precise and defined action that takes place only and exclusively in the physical completeness and perfection. It conquests its shape depending on the personality of the Ego that does it, because it is intimate and subjective. For this reason, Education to Theatricality, and the laboratory, in an experience that everyone can live, even if we talk about disability or diversity.

\subsubsection{Interdisciplinary}

Education to Theatricality is a science that includes different of disciplines such as pedagogy, sociology, human sciences, psychology and the performing arts in general. The scientific basis of this discipline allows us to apply it in all possible contexts possible and with any individual, because it keep the man as he is in the center of its pedagogical process. One of the fundamental principles of Education to Theatricality is the construction of the actor person; the main aim is the development of creativity and imagination through a scientific training leads by the actor on himself.

This science does not want to transform a man into an actor-object, molding him to product shows that are prepared just to be sold, but to enhance his individual qualities respecting his personality. The final product plays a role linked to the training process of every man, giving a different value to every different personality. Fundamental to the definition of identity and to the development of imagination and creativity is the conservation of the skill of expression, which represents the starting point, the key element for comparison with each other.

\subsubsection{Difference}

When we talk about difference and above all about disability we have to wonder what are the characteristics of a human being, that make him unique. Being something important to someone else, be in relationship with, have a relationship with someone, can definitely restore dignity to the person. But, before that, the essence of man consists in perceiving their own individuality and identity. He must be perceived by himself as the undisputed leader of his gestures and its actions, who can make he choices and changes. He should be a creator of reality and, above all, the unique artist of his own life. The Education to Theatricality promotes a process of awareness of the Ego, discovering the body and its expressive potentialities. We can imagine that our body is a factory of information which are coordinated and modulated by the Ego. It can be said that the body exists because the Ego exists. The Ego exists because it synthesizes and unify the bodily activity.

And when there is a disability? We can say that we have overcome the old physiological and psychological conception of the body as a given structure, regulated by its own laws, and the Ego as something totally independent from the body but that creates a relation with it and uses it to express. So we realize that all those definitions about a disable body cannot exist anymore. A man must be able to act, to create, to define, to put himself on the line to construct his own real identity. He must be able to be creative. Creativity and imagination are a sort of intermediate space where there are no models, there are no deficit or impairments: man as human being is creative.

\subsubsection{The Creative Subject}

Education to Theatricality is trying to define into strictly scientific terms the process that leads to the development of a creative act. The creative subject is, in fact, object of an interdisciplinary debate: on the one hand, psychologists 
and neuroscientists are trying to identify the individual characteristics and the mental processes that determine the development of creativity, on the other hand becomes always stronger the reflection on these issues in artistic and expressive field and in pedagogy, too.

Creative man is, in truth, a category of contemporary thought, defined in the second half of the twentieth century. In theater, on horseback nineteenth and twentieth century, with the directors-pedagogues, the concept of creative actor started to be developed and we can speak about the actor as a man who knowingly uses himself to express.

Only from the cultural revolution founded on the figure of Jerzy Grotowski in 1960 and with the development of concepts of art as a vehicle and performer it begins to talk about creative man by nature that uses art, or better arts and expressive language, as a vehicle to consciously work on himself. Beyond the distinction between of artistic genres, Grotowski redefines the idea of art as a field of research about the essence of human existence. Creativity, therefore, ceases to be a matter solely for the artists or for the genius and becomes a characteristic of every human person; this idea is also supported by neuroscience for which each person has a creative potential to develop.

Art is a great opportunity to develop this potential. Precisely for this reason, Education to Theatricality focuses on the creative subject: the theater workshop becomes a method of work based not only on the intention to transmit knowledge, but, above all, on to lead every subject to form himself through a practical experience. Through sensory stimuli, through the movement, the subject experiences in practice (learning by doing) and learns or enhances both cognitive and conative factors that modulate the expression of creativity. The first are determined by the ability to develop different answers to the same situation- question (lateral thinking) or in the ability to consider a problem from different points of view (the mental flexibility); the latter are determined in the development of certain personality traits such as openness to new experiences, willingness to run the risk of making a mistake, attitude to the fascination for the unknown, ability to withstand dominant currents of thought and love for creative activity.

\subsection{Education to Theatricality and Creative Movement}

Talk about creative action in the field of expressive means also introduce the concept of "creative movement". Creativity becomes action linked, firstly, to the body and the movement. The creative movement is the development of continuous creative acts, one after the other in time and space, which leads to a simple but fundamental anthropological concept: the relationship between human being and movement. A man is always on the move, immobility is quite impossible. The movement is a specific element of life and plays a central role in relationship with the Ego and with others.

Movement does not arise only from a material need or by an act of will, and it is not just linked to the human muscle-skeletal system: it is also emotion. For this reason, creative movement is connected to the relationship of a subject with the world of creation through the expressive arts and to an analysis of human being and his life, that weaves connections between man and body, between body and expression, between movement-body and creativity. The discipline focuses on the discover of the body in its totality and on the preparation of this instrument as a means of expression. It is important, in fact, not only become aware of the various joints of the human structure and of their use in the creation of rhythmic, gestural and spatial patterns, but also of the inner mood and the attitude in relation to action.

Education to Theatricality, in the study of the creative act and in its realization in the "creative movement", can be considered a science that determines its practice starting from a precise conception of man and his existence. In particular, it is connected to Delsarte's conception about man as an indissoluble unity of three distinct elements body, soul and intellect- which are interdependent and always in close relationship. It is interesting to note that, regardless of a specific philosophic conception, theories of this science show a sort of independent efficiency: Education to Theatricality takes into account and verify physiological and neurological processes that govern the sphere of the human body. In fact, this Science, has collected the theatrical practice of directors-pedagogues and has made their axioms systematic, drawing from them a universal knowledge.

Creativity, as the ability to transform, build and produce, can be realized in the creative act, that is in an action to which underlies the development of a specific process and a specific state of being. Creativity refers to a productive activity, however, is not only linked to originality (the invention of new ideas or expressions), but also to the reworking of existing elements. The subject, through creativity, transforms the stimuli from outside composing them in a new, unique and personal way; in a study about this issue we can read that: "The creative act [...] is always caused by the encounter between a stimulus coming from the outside and a proper state of consciousness. Through creativity, the subject face in a personal way the inputs of the environment and adapts himself modifying them according to his needs. Creativity requires a constructive way of facing reality and the skill to accommodate 
experience to be able to break the patterns influencing reality. Create means be able to product something, it is an activity that can produce something out of nothing, but also [...] it means to be able to elaborate elements that already exist in a new original way, to confer to them the character of novelty and uniqueness; with the creativity, the various experiences collected year after year are retrieved into memory, combined and used in a way consistent with the situation" (Oliva, 1998: p. 29).

In the field of expression, creative act is outlined as an action which involves the totality of the human being. To obtain a creative act all elements of the "trinity of the person" are stimulated and used: the intellect in its dimension of mind (fantasy and imagination); the soul in its dimension of emotion and feeling; the body in its dimension of gesture and movement, identity and shape. Here is the chart that summarizes the theory of the creative act: Table 2 (Source: Oliva, 2005: p. 310).

Table 2. Creative Act

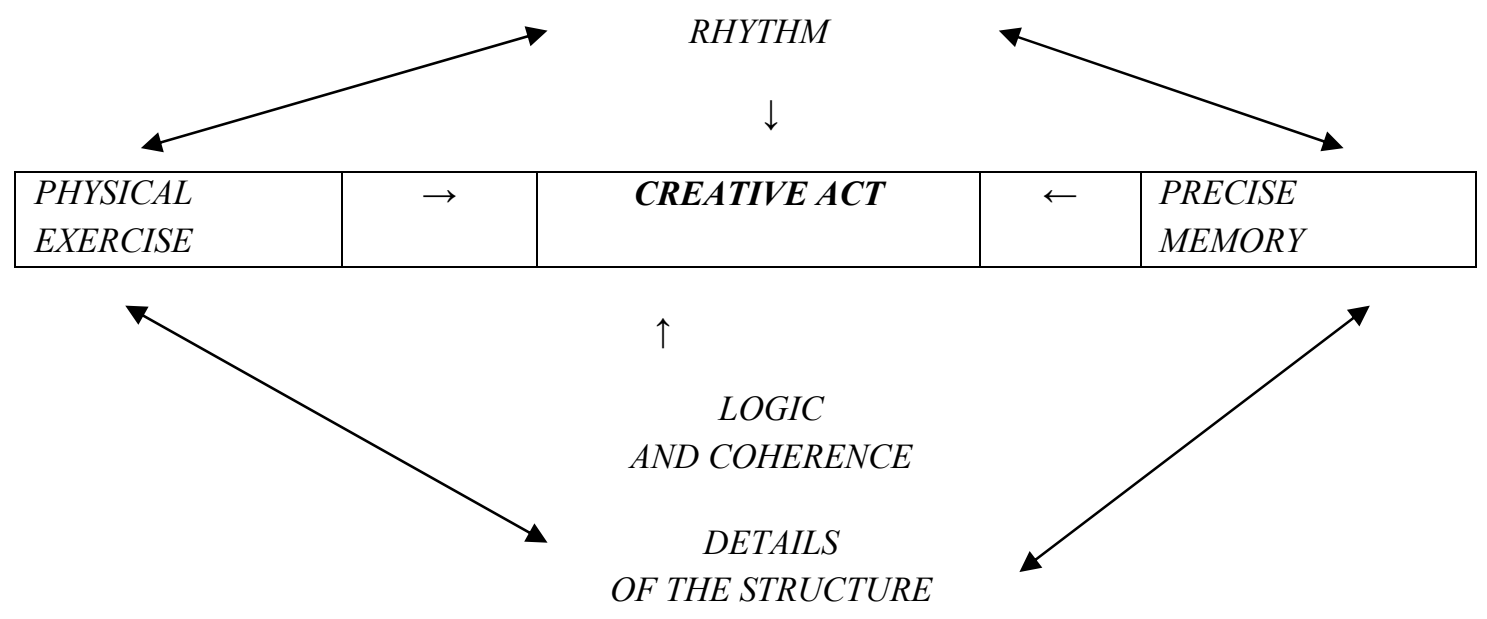

Starting from Grotowski's research, Education to Theatricality, as we can read in the diagram above, has defined the creative process as a correlated set of a series of elements: a) the physical exercise as a starting point (the body of the performative act); b) the development of it to determine a detailed structure; c) this elaboration processing is determined, furthermore, inside a precise rhythm that governs the action developing it in time and space; d) the necessary presence of a memory, that is a precise emotional condition. As scientists and neuroscientists affirm, there cannot be creativity without a connection to emotional affair. It can be seen that in the memory, in the physical exercise and in the logical structure of the creative act are involved respectively, the soul, the body and the intellect of the person.

\subsection{Creative Act and Personal Growth}

The complexity, the richness and the globality transform the creative act into a fundamental point of any expression path related to artistic languages; so more if that activity can be used to create educational or training programs. Cesare Scurati defines the laboratory as that place where "you can tackle new routes of exploration, [that allow you] to implement new methods of interaction [...] based on the quality of supervision, of support and of reciprocity, and where it is enhanced the productivity of each one" (Salati, Zappa, 2011: p. 2) so the creative act becomes necessary and indispensable. Without the improvement of personal production we cannot build a real process of growth and development of the person, but without putting at stake the whole person we can obtain not even the development of a creative act. The deepest experience that a person-actor can live is, therefore, the production of a creative act. It encompasses, therefore, the synthesis and the apex of the cultural theatrical and pedagogical revolution that has involved the twentieth century: the perception that the Man has of himself as the heart of the question, capable to change the nature and the events, able to live social changes, subject and protagonist of his life.

\subsection{The Theatre Laboratory as Educative Methodology}

The theatre laboratory becomes a place of artistic research par excellence: "the word itself reveals the nature of the process. It is not a kind of theater as we can usually think, but rather an institution devoted to research in the field of theatrical art and in particular of actorial work. The performances of the Theatre Laboratorium constitute a kind of operating model in which they are put into practice all the researches carried out in this field. In theater world, this is 
known as the Grotowski's method. [...] There is a tight contact with many different disciplines such as psychology, phonology, cultural anthropology, and so on" (Grotowski, 1970: p. 11). Moreover, Education to Theatricality uses only this instrument to help man to educate himself. The process, described and schematized in the previous section, is carried out within the laboratory opening the door to the development of individual creativity. Concretely, this process is divided into two parallel paths: one focusing on the discovery of Ego, discovering personal skills trough a physical and emotional work. The second one aims to the realization of the Ego, through a constructive dialogue with the other. So we have two corresponding technical phases: the monologue and the dialogue. In the phase of monologue we have: "Concentration, observation, breathing, communication, fantasy, imagination and improvisation, then we have the voice, the body, the memory" (Oliva, 1999: p. 93); in the second phase, that of dialogue, there are "sharing space, contact, learning to listen and communicate, the voice, body, the rhythm and the understanding between persons" (Oliva, 1999: p. 93). In general, "the theater workshop seeks to influence three dimensions of the human being: the physic one, the creative one and social one" (Oliva, 2005: p. 236). Even the setting acquires a great importance: the laboratory is a place and a space separated from everyday life in order to facilitate a temporary suspension of routine to allow a more accurate exploration and construction of Ego. So it is possible to build a deeper interaction both at the individual level and group level.

In particular, there are three levels on which is based the whole process. There is a first individual level, in which the person-actor gets in touch with himself through the phase of the monologue; the skills used in this monologue must be projected in everyday life, in order to obtain a greater gratification. Then there is a relational level, in which instead is experienced the phase of dialogue, that is the relationship between the different person-actors; "To try to establish an emotional contact with the partner, it is necessary to develop some others human faculties, such as the accuracy and control of the Ego" (Oliva, 2005: p. 236). Finally, there is a group level, wherein the person-actor experiences within the group. This process requires a fundamental figure: the conductor of the laboratory. He is certainly a person-actor, but must acquire a more important skill more: "He must be an educator-actor, searching with this word to interweave two fundamental dimensions: the theatrical competence that stimulates the artistic abilities of the students and on the other hand, the specific pedagogical skills of an educator" (Oliva, 2005: p. 237). His task is not to explicit everything, but provide stimulation and directions which are then interpreted and completed by the student. It can be said that the conductor assumes the role of facilitator, it is not limited to transmit knowledge, but it helps and supports the process of learning.

The theater workshop, as the theater itself, is essentially action, or more precisely construction. This concept can be explained starting from the etymology or the Italian word "formazione" that refers to the idea of model something in such a way to make it assume the desired shape; everything is based on the action of construct and create to something specific. This action embodies "the idea of a form, in the sense as a special way to express themselves with words, writings or with any other artistic activity, as a way of being, living and behaving. (Oliva, 2005: p. 237). In general, the word "form" refers to a static association, but actually one form is reached only through a series of specific movements. Getting in shape means live a certain process that is summed up in this precise form. For this reason, the terms "form" and "action" are unified, to bring up the idea of something that is created in the moment of action; the motion given by the action, however, embodies a value that is given by the form. To demonstrate this idea, we can submit an example of a real experience of a student during his training workshop: "I always thought that the best way to express a certain feeling was using a non-verbal language, in particular dance. So, in case of sadness, for example, I believed that it was enough play a music that stirred me out of sadness and dance, making sure that my body, molding with the rhythm of music, was completely free to move in space; How else I could communicate a state of mind, except through a movement of my body without any constraints? However, I felt that this was not enough: it lacked a piece to complete the puzzle and I did not understand which one. When I attend the lessons of Teatri d'Animazione at the university and Laboratory of Creative Movement, I finally understood which was the problem.

While the music was playing and my body was following it, in fact I was not communicating anything, I was just venting something. The expression of the feeling was not clear because my body was left in the lurch, in fact the subject of the mood was the music and not the body anymore. Carried freely on the music, I lost the original intent (that is communicate a mood) and therefore also the very meaning of what I was doing. There was no dialogue between my intellectual and my corporeal being. Thanks to the laboratory I have understood exactly what I said: I am at the same time body, soul and mind and I can not think that one of this dimension can exist without the others. To give intentionality to my action, then, I have to put my body in close communication with my mind: my movement must be created by intentional forms" (Testimony of a student of the course of Teatro d'Animazione, Faculty of Education, Catholic University of Milan, Italy). 
The theater workshop, as a process of attribution of meanings, can connect the action with thought and vice versa. For this reason, while giving ample space on the physicality and action, it not neglects the essential moment of reflection; this allows to acquire a greater awareness of what has been accomplished. The reflection, such as promotion of the comparison, is designed as a central element because it allows to revise the process through the sharing of commonalities and differences of the experience. The aim of the conceptualization of the experience is to allow a greater understanding and help people to seek shared meanings. This is our idea of training.

One can understand, therefore, the importance of this educational idea through the Theater Workshop: it is based on verbal and non-verbal exercises having as objective a more intense conscious and interpersonal relationship. Furthermore, the fact that everything takes place within a group (which must be small to make a good job) encourages socialization, very important for education. Through it, every individual discovers himself. But there is another objective promoted by the Theater Laboratory: the development of creativity. Inside the lab, in fact, everybody can express their specificities and diversity: each one has a message to communicate through his body and his voice, which allows him to find his identity and to accept others as a person who has something to say; reciprocity becomes the place where manifest meanings, which are the simply result of the creative process led forward by each. Through the movement of our body, creativity becomes action and thus leads the actor-person to realize a creative act. Inserted in this described process, the performer has the chance to experiment, to dialogue and to listen to himself, but always in new ways; so he is forced to seek new ways and to go beyond his own beliefs, arriving to create actions and movements imbued of creativity, because he becomes the one that creates something new. In other words, "the actor-person [...] is the master of his own creativity, which originated by a great inner strength, is the bearer of authentic values in which the spectator can see himself" (Oliva, 2005: p. 231).

\subsection{The Role of Theatre Educator}

Modern life requires a rapid adaptability by man. The flexibility is not only required in the workplace, but it's part of everyday life in the studio, in sports, in family, approaching to new scientific and technological discoveries. It is necessary then, in particular for professional educators, help the learners - that can be children, youth or adults - to build a good awareness of itself, a provision to interpersonal relationship. Education is the science of change since it is the finality of education. A change which is not only a modification of the conditions of subject's life, but first and foremost as a transformation of the perception of himself. The task of the educator is to provide the resources and situations more suited to the change. Onorina Gardella says something more: "The educational work to change something is always relational. It always presupposes two or more subjects, two people in their entirety. It need a comparison or a conflict with the other" (Gardella, 2007: p. 34). And Luigi Diotti says: "Education is not made just by aims, content, methods and means, because in practice it is the concretization of a relationship between two people and it is influenced by the structure of their life" (Dotti, 2006: p. 87).

The conductor of a theater laboratory has the opportunity to influence the relations and the organization of the group through the construction of the setting of work and the care of its dynamics. He has the main function to hold together the entire group and help each person to take an active part in the theatrical action. The director educator has to be able to activate a context of play and to promote a positive affective climate. Every member of the group should have trust in the operator before to have it in himself. An atmosphere of actual trust will permit to the group members to feel safe enough to express themselves. Only when the student will have the certainty of not be judged he may invest part of himself in creative work. Salvo Pitruzzella says: "Come into play" implies an investment of psychic energy which is offered to the other, in the form of collaboration, of trust, of capacity to take risks; moreover there is the need for everyone to own a proper communication space, that should be recognized by the other one. The educator must be the guarantor of this balance, but at the same time can't be an external controller: on the contrary he is a participant of the process, being aware of his emotional and imaginative investments» (Pitruzzella, 2009: p. 21).

Flexibility, adaptability and elasticity are qualities that the conductor must necessarily possess in such a way to be able to adapt his educational proposals to the environment and to the people he works with. He must be able to translate questions, convey messages and calibrate requests, in relation to the age of the students and the characteristics of the group. If the educator understand which are the factors that inhibit creativity, he will be able to help the student to understand and overcome them. Gardella suggests: "In this sense, the educator is also a counselor because it supports the subject towards the discovery of the personal identity. He cannot bind to precise patterns this self-discovery, he has to suggest new ways, see goals, recognize and propose from time to time the possible choices, the opportunities, the new aims, the real opportunities" (Gardella, 2007: p. 55).

The theatrical educator, through his function as director, is able to trigger a creative process. Theater becomes an 
instrument, a sort of physical and mental space in which you can share a fantasy. One of the tasks of the educator, in particular of the theatrical educator, is the contribution to a harmonious growth of the Ego. Helping a person to become aware of his own body means help him to discover himself and to make better use of his personal resources. The educator, in fact, offer resources that should be not just consumed, but reworked by the subjects in a new energy (Triani, 2002: p. 29). He asks not only to do, but especially to think about what you are doing. The conductor of the laboratory must activate efficient situations in the theater simulation from an educational point of view. To make sure that the personal creative skills can be developed by education, he has to offer adequate tools and contents. Therefore it is essential to prepare an educational theatrical plan with specific and prefixed goals.

\subsection{The Planning Activity in Relation to Expressive Arts}

Planning activity is a peculiar action of the educator, in fact he has to be able to give sense to actions, through a continued openness to a creative life and to its possibilities. He should not think in a standardized way, but has to create a vision that aims at the human being's personality, considering, at the same time, his relationships, his social and cultural context. This is because "the planning activity does not require you to work only to achieve something, but also to work on something" (Santerini, Triani, 2007: p. 64). Planning activity allows you to avoid the risk to make trivial and superficial the educational relationship and the professional work of the educator, whose specificity is precisely to be an agent of human development, that is individual and collective. Once you understand the importance of planning in the educational world, you have to answer to another question: how to plan? And through what tools?

It is essential that each educator tries to answer to these questions when he has to face a group of people. There are so many theories in educational field that it is really useful and necessary to understand which one to choose to plan reasonable activities that aim at achieving specific objectives. One way may be to choose education through expressive arts, that is, an education that prefers artistic expression to develop knowledge, awareness and discovery. Any art presupposes creation, preparation, research, experimentation, evaluation, as well as to be ready to put yourself on the line. It is clear that to do that the artist must possess precise skills, otherwise, if everything was left to a free improvisation, would decay the deepest sense of his actions. This is meeting point between art and education; in fact education is considered an art, too. Pedagogy assumes the same actions, the same projects, the same research of sense of art; and this also can't be improvised. "Creating a work of art, a man stretches out towards the achievement of that form of the Ego that is already inside himself. His goal is to reach it. As well as the work of art also the process through which the subject is forming emanates from the desire to reach the actual form of the Ego. Every man aspires to a perfect and authentic existence, despite the difficulties" (Musaio, 2007: p. 239).

The artist as well as the educator seems to live a paradigmatic experience because, even with all its intentionality and will, he cannot not reach fully the beauty of things that surround him: the artist tries to reach and approach to the inmost reality of things and people, through his works and the relationship of love that takes over in the implementation phase. The educator tries to reach the most intimate Ego of individual through the action and the educational relationship.

"Education is an experience permeated by the component of risk, but that never ceases to attract because of the beauty of human implications. Education can be seen as a fact, an act and an event from the contours not always well distinguishable, especially if you pay attention to the challenge of the postmodern culture that project educational subjects in a context that seems to have lost the references to help people to develop an authentic relationship with himself and reality" (Musaio, 2007: p. 12). In addition, every educator, while still aiming at a deep knowledge of every person, will never reach a level of total understanding. For this reason he has to puts into play all the instruments he owns, using not only the reason, but also the intuition, which focuses precisely on the immensity of the human being. It is this kind of reason that opens the door to wonder and to discovery. An educator to work and to create works of art, has to use those tools of expression. If it is true that art is a vehicle, we can affirm that it is a powerful and effective mean that opens up the doors to an education which aims at the innermost part of Ego; «Maritain has defined a creative intuition, "as a dark grasping his own personality and the things in a knowledge through the union or through the connaturality that arises in the spiritual unconscious and becomes fertile only in action" (Musaio, 2007: p. 25).

To this first characteristic that unites art and pedagogy, we can immediately adds another: both these "worlds", in fact, want to animate life. This means give blood, give shape to daily lives, giving sense, to rediscover their routine under a new light, to live their relationship through different dynamics. The soul is the most inner part of the Ego, the most hidden and silent, but, at the same time, even the most noisy, that "shouts" inside, that shakes us. The soul is the "storm" that shakes, that haunts, it is energy; it is the most irrational and emotional aspect of man: "[The word 
"anima"] brings us back to the Greek word Anemos, which means wind, or blow. There is a wind that blows out of us that can be as light as the breeze or shocking as a hurricane; and there is also, using metaphorical language, the wind, the spirit, that, according to various religious traditions, was "breathed" into us. A dynamism that work without being "grabbed", which you can hear and feel, but not see" (Iori, 2012: p. 13). This helps to confirm that "projecting life to pursuit beauty can emerge as one possible path to search certainty, something to grab to not disperse in a fortuitous combination of events and variables" (Musaio, 2007: p. 27). Through its symbolic language, art has always helped the individual to approach the meaning of life and to reach that level of knowledge that man can only perceive because it does not occur in his eyes as matter; in other words it helps man to find his voice.

This is a very difficult moment for the contemporary man, because it is characterized by a new search for values, by a crisis at quite every level of life, by an education permeated by uncertainty and doubt, it is absolutely necessary an intervention to re-evaluate the situation, that restores its value, through a watchful eye on the finality and tools needed to reach it. The bigger investment of every educator is giving blood; in fact, the contemporary crisis that man is experiencing is the bearer of discomfort and negativity, it can also be seen as an opportunity, a stimulus, a challenge to renew the human existence in all its profiles. "In times of difficulty we must have the courage to invest in educating, because it is the point to start again" (Iori, 2012: p. 10). If it is true that "education is based on a planning activity that should make full and beautiful the existential experience, even in adverse or difficult conditions of crisis" (Iori, 2012: p. 10), then it is its duty to accept the complexity with realism in order to stimulate its authenticity without falling into resignation.

In this context, the proposal carried out by artistic and expressive languages is perfectly embedded. Its most important characteristic is to be able to mobilize the most intimate resources and potentialities of the person, in order to allow a training experience that forces a continuous dialogue with every element: body, soul and intellect. These languages require a regular exchange between theory and practice: planning activity with expressive arts proposes a concrete experience, based on physical actions, because it consider a human being as creative and to create every human being need to practice, in the true sense of the word. But to give sense to a plan, the use of these languages must rely on a concrete theoretical basis. Without this ongoing relationship, the planning activity (as well as education) would not have sense. There can't be one without the other; doing does makes sense if it is not accompanied by a reflection and by awareness, and viceversa. What has been said hitherto may seem obvious, but it is not: in contemporary days, when it is tacitly affirmed the idea that rationality rules on the most sensitive and creative part of the human being, we can't stop and try to find into the most pure expressive part of us (left on the sidelines and maybe forgotten) the answers to try to propose an education guided by values and certainties.

Bringing to light this most intimate aspect of man, the artistic methodology is presented as a pedagogical tool based on the co-construction of activities which "aims to enhance the vitality, the expression of people, the interests of groups, of organizations, through a series of expressive, cultural, recreational interventions, based on a logic of participation" (Iori, 2012: p. 15), if fact its aim is helping people to find a meaning of life. For this reason, the educator who want to plan following this idea must also assume the role of "animatore" (animator) : to be an "animatore" means promote actions directed to the soul of people, so we talk about "anim-a-zione" (soul in action) . Through this type of training activity, an educator, focusing on the soul of the people, should work on the sensitivity, expressiveness, intersubjectivity and imagination, which are the fundamental dimensions of man. Its goal is to pull out "the artist" that is inside every human being and promote the wandering side of each one. A human being who wanders, looks, travels and simply makes mistakes to find himself.

This training allows you to express your Ego and to give voice to what appears silent; in addition, an experiential perspective is supported because it want to teach to do following proper ideas and dreams. This is the look of someone who is ready to welcome and enhance every movement/action: "we do not want to define stylistic-executive models, but to build pathways able to reflect the thought and the emotion of the body" (Iori, 2012: p. 107). The body is a just another feature of expressive arts: in fact, they propose a model of education in which the body participates fully because a human being can't exist without it. Unfortunately, there is the risk to consider the human being without considering body, because it is dominated by the intellectual / rational component. But in this way a human being is not considered in his totality and in his fullness, that instead is promoted by the artistic-expressive vision: "it favors the use and exploration of the body in order to experience new and different ways of feeling and being, for access to emotions which are nested in the body, and so they are difficult to represent using language, and to transform them into new gestures that accompany the change and the development of skills" (Iori, 2012: p. 109). This is crucial because the human being needs to narrate and narrate about himself. Expressive arts, especially theater and dance (if we talk about creative movement), favor: "the discovery of dramaturgic body, that is a body able to tell small stories and emotions through its experiences [...]. [This] is important [...] especially 
for the improvement of the capacity of relationship with the Ego and with the others. It is important even for the relationship with cognitive intelligence (a dramaturgic body brings self-enclosed his history, it is a sort of body-chest that contains physicality and emotions, it is the body that communicates, even without the use of verbal language)" (Iori, 2012: p. 124).

In conclusion, this reflection provides a starting point for responding positively to the question that was asked initially: "Why a planning activity through expressive arts?". Because they offer the opportunity to not follow models to human being, but to be a model of himself. Through the proper tools of art, every man can tell everything about himself, without excluding any existential component, allowing him to considered himself the protagonist of his action. This is true at any age, regardless of sex and culture: the art is part of human life and the creativity, which is present in every person, can be cultivated thanks to the tools of expression that art itself offers. Then, getting in touch with himself and putting himself in discussion to find himself again, a human being can create deeper relationships with others, and this is an opportunity for social integration, which is not limited to a superficial level, but, on the contrary, has its roots into a truer and deeper level, because he made a process to give a new meaning to life. Thus, "the identity of any person enter into a relationship through a narrator reality; action, speech and gesture become instruments to investigate life" (Iori, 2012: p. 144).

\subsection{The Laboratory. A Methodology of Pedagogic Work: Improvisation}

"Improvisation" is one of the most important words of theatre of this century. Improvisation is one of the most helpful methodological instruments to train an actor-person (Pilotto, 2011: pp. 48-64). Improvisation is an instrument to understand human and theatrical situations. During improvisations, the actor can create actions that then can be used during the performances. Pedagogue-directors (Stanislavskij, Vachtangov, Copeau, etc.) consider improvisation as one of the most important exercise of the training of the actor. During improvisation every actor can collect a sort of expressive and emotional baggage. They consider improvisation as important as the study of the body movement in the creative process, because it helps the actor to improve his expressive verbal and not-verbal skills, to develop his skill to react to unexpected changes. Improvisations hanged in the balance between precision and spontaneity, instinct and self-control, and many man of theatre, such as Brook and Grotowski used it. Grotowski considered improvisation, showed by the spontaneity of the movement, as a starting point.

Pedagogue-directors consider the repetitiveness of the performance like a limiting factor for the theatre itself. The daily rehearsals provoke a sort of mechanicalness and automatism that are the cause of actor/character's "not-life" on the stage. The director, during the training, can introduce the exercises of improvisation to change this condition. Sometimes improvisation can be even the starting point to create a performance. An actor, through improvisation, can experience different situations that are not real, because theatre is a place where everything can be, different feelings and true emotions. So, the pupil can get know better himself and meet the other, who can be an actual other, like the audience or a partner, or a fictitious other, like a character.

One or more persons create an improvisation when they produce an action, verbal or not verbal, taking as starting point a precise subject and developing it as it goes along, without being constricted to follow a written script. Improvising means that an actor can act spontaneously, according to his own imagination, respecting some given conditions and being aware of what he is doing: in fact, pupil's gestures and words must not follow a script, but he has to pay attention to the stage and to others to create a performance that makes sense. The verbal improvisation is more difficult than the not-verbal; an inexperienced student cannot be able to transform fast his actions in words, and can feel inhibit to reveal himself to others.

The improvisation can be a helpful instrument to train actor-person's spontaneity, only if the members of the laboratory trust each other and feel secure. So, the Educator to Theatricality should create a proper situation, where the pupil, as single person, can discover himself and his skills, in relation to others and where he is aware of the risks and ready to unexpected. Improvisation helps pupils to develop their identity, transforming an experience of life that can be stimulated by a script or by a personal idea, in a personal experience. Improvisation can be really educative, because it encourages introspection and reflection. The pupil that is able to improvise will be ready to act in an unknown place; he will not be afraid about new meetings or situations, not only on the stage but even in the daily life.

The laboratory uses the open technique of improvisation, both during the preparation phase, when pupils are trying to understand which is the best solution to convey a particular meaning, and during the performance. Theatrical improvisation cannot be "provisional"; it must catch the spontaneity of a reaction to an unexpected event in the daily life. Then, we can use this reaction in a controlled situation to better understand circumstances. Improvisation is an existential fact, something to penetrate, to comprehend, and to mediate reality. Improvisation technic is useful 
because it is improvised. A precise "technic", already experienced, does not exist, it would create just stereotypes. A determined technic does not exist. The actor should just train himself to cancel his resistances and to transform faster his own psychic impulses in actions. The more an actor is matured, the more he knows, the more he must train. There is not a technical model to follow to get a good result. The exercises must be created for each group, to stimulate imagination and creativity. The Educator to Theatricality has to understand what pupils can create and to recognize the original part of their creations. Then, they can suggest altogether different expressive alternatives. He has to keep alive his imagination and the imagination of his pupils, but he has to be unobtrusive and confident. He has to value the new creations of the group and suggest new goals. He has to accept the group and give new stimuli, he has to be with the group, live with the group and aim to pass over every determined structure.

The Educator to Theatricality's role is to quickly recognize how much of original the students are able to discover and to propose different alternatives of expressive nature, of diagnosis, of close examination, etc., when the group would be ready to also be satisfied with a pleasant result. He must constantly maintain vigilant and vital the strength of the imagination of the actor with a type of discreet intervention, intuitive, confident. He must immediately esteem the unpredictable novelty that the group has been able to create, and together to point out another finishing line $\mathrm{He}$ must know how to accept the physiognomy of the group and to relaunch the creativeness. Its assignment is to be with the group, to live with the group, and to extend beyond every situation determines a priori. He must dynamically balance the value of the liberty in the assumption of an exercise and together to provoke the inventiveness.

The improvisation in the laboratory is a methodology of fundamental job. The exercises must not become pure free gymnastic exercise. They are open and verification of the expressiveness of a gesture, of a word, of the sequence of gestures, of a movement, of a form, of an action. The expressiveness must have the tendency to overcome every time (improvisation) the spontaneous or repetitive expressiveness. Every action must be: new, precise, creative, expressive, logic and communicativeness.

\section{Second Part: Workshop. The Theatrical Workshop: Exercises}

The objectives of the theatrical workshop are: self-awareness and discovery and development of creative potentialities.

The activities are listed below, they develop exercises respect the languages:

- Non-verbal language (the gesture and the mime through the neutral mask and the movement through the creative movement).

- Verbal language: the theatrical reading.

The exercises are practical examples of activity. They must be modified according to the formative demands, according to the age of the participants, the characteristics of the groups, the personalities of the students.

For children: the exercises must be turned into activity of game. Every "theme" it must have transformed through the imaginary one.

\subsection{Neutral Mask}

The neutral mask is very important for the pupil's work (Pilotto, 2011: pp. 48-64). The neutral mask is linked to the evolution of the new mime during our century, and Lecoq (the most important expert of mime ad theatrical pedagogy after Copeau) defined it as a base, on with the differences of other masks can be showed up. It has no expression, and it does not represent a specific character: it transmits to the viewer a state of calm and silence. Copeau was the first one that discovers the importance of the neutral mask in the twentieth century: "From the moment the pupil wears the mask, he free himself. He better experience his inner world". Copeau used the mask during the laboratory, so pupils concentrated their expressive skill in each little detail of their body. In fact they knew that the face could express nothing because it was covered by the mask. The actor trains his body to do just significant movements to communicate to the viewer a specific message. So, to study gestures, the actor must stylize them, he has to divide them into simpler gestures. Every gesture should be linked to a specific part of the body, so they can be analysed one by one and the movements can be studied in relation to different dynamics, for example the normal velocity alternated with a slowdown velocity, or the change from an explosion to a sudden immobilization. The neutral mask allows pupils to get closer to a sort of neutrality condition, which is a sort of condition very hard to get. The pupils can understand the essential mimic of the daily routine just knowing that particular state of mind, when the human being resets himself to zero. So he can really be opened to the rest of the world.

To wear the neutral mask 
To wear the mask. It is a rite.

Neutral position. Mask for earth to the feet.

To fix the mask. To focus. To go to pick it up. To fold up the whole body. To slowly draw near to the mask. To pick it in hand up. To observe it.

To identify with it. To wear the mask.

Neutral position with the mask. The student listens himself and his body.

Concentration. Immobility. Silence.

The neutral mask doesn't have expression of the face. With the neutral mask the student cannot speak. Expressiveness is not in the voice, it is not in the face, but it is in the body.

The neutral mask is an exercise, it is not to recite.

The simple gesture

To wear the mask. Fixed look before. Don't look at the body. Don't touch the mask

To make a simple gesture (to move an arm, to move a hand). To return neutral.

To perceive the gesture. To complete the gesture with slowness, with ampleness, with simplicity.

The movement is stylized. The gesture has a beginning, a development and an end.

To use the arms before, then the head, then the bust. To come to create some forms with all the parts of the body.

Made a gesture return to the neutral position.

The exercise with the neutral mask is beneficial for to develop the awareness of the body.

\section{Mechanization of the body}

Standing up or sitting down. To wear the neutral mask. To mechanize the body starting from a part of the body. To follow the sequence: hand (right or left), wrist, elbow, shoulder, neck, head, shoulder (left or right), elbow, wrist, hand. C-Spine: bust, possible pelvis. Legs, knees, feet.

To bring the whole body is in movement. The movement is slow. It is necessary to articulate a part of the body to the time.

To create some forms with all the part of the body. The forms are of the statues.

You builds a statue. The movement leaves again from a part of the body. You mechanizes all the I cover. You creates another statue.

\section{The mirror}

Be couples. Face each other. To wear the neutral mask.

A student conducts. The second student copies as a mirror all the movements.

After some time to change conductor.

The movement of the couples must be in unison almost perfectly. The conductor must realize movements and simple and slow gestures, the mirror must develop a good listening.

The mirror can be performed in the three dimensions: standing, in knee, stretched out to earth.

\section{Awakening exercise}

The "awakening exercise" is composed by three parts: at the beginning the student, lying in foetal position, discovers his body, as it was the first time. So the body starts to move, one part by one. Then the pupil starts to move around until he meets the other. When they meet they start to get know each other, discovering each other and coming into contact.

The exercise can be realized in silence, following the natural rhythm of breath, or following the sound of percussion instruments or an appropriate music. The pupil must not touch himself while he is exploring the surface of his body, because the contact would relieves the energy, birth thanks to the muscular tension between the hand and the body.

The neutral mask is helpful to allow pupil to train himself, because trying to get a neutral condition is very hard, and it requires a lot of attention and concentration. The development of this kind of skills can be very useful to the training process of every person. 


\subsection{Creative Movement}

No art can be described or explained. Creative Movement produces through its effect on the spectator you try very simple (Oliva, 2011: pp. 29-46). Creative Movement (or Dance) is pantomimic and it consists of pure representative movements. We are able to understand the sense of those movements because we have just done them, or we can easily imagine ourselves doing them. We do not need to think them over, to wonder which the purpose of each gesture is. We can immediately put together the movement and the goal, thanks to the sympathetic muscular memory. Our muscles remember the specific result of a precise series of movements. But, what does it happens when dance is not representative, when dance is not a pantomime? The same thing. Thanks to the "sympathetic" kinaesthetic, we react to the dancer's impulse, manifested through a series of movements. Then, the movement is the link between dancer's purpose and our perception of that purpose. To a certain extent, we can assert that body does not execute any movement that is just totally representative. In other words, body cannot be obliged to do something that it cannot do.

\subsubsection{Metakinetic}

Movement is an instrument to transfer an aesthetic and emotive concept from the awareness of one person to the awareness of another person. Kinetic is the name of the physic movement. Metakinetic is the psychic correspondence of kinetic. The correlation between these two concepts is based on the theory that "physic" and "psychic" are just two different sides of the same background reality. This article will explain neither metaphysic theories nor what we prefer about the relationship between physic and psychic world. We are interested in the connection between physic movement and mental, or psychic, intention in Creative Movement (or in dance). Metakinetic can seem a strange word but is the only one that we can use to formulate one of the most important principles of modern dance. We have just stated that one of the four most important discovers of modern dance has been the discover of the movement, that can be considered as substance of dance as well as sound is considered substance of music.

The second discover is metakinetic, even if nobody has discovered it: it has always been true. It was true when the primitive man communicated the sense of mystery of death and when he excited to fever pitch his tribe, leading it in a particular dance. It was true, and partly recognized, in the great era of Greek theatre, when the movement was the most important element of drama. In fact, the chorus danced and sang to emphasize the most important tragic moments. So, the movement was used, as Gilbert Murray has said, to express "the inexpressible essence of emotion" that just the rationality (word and pantomime) could not communicate. It was true during the long years of classic ballet. Without metakinetic the viewer would have looked at the dancers, who were dancing on their tiptoes, in the same way they would have looked at a feather floated in the air. It was the awareness of the force of gravity, which fastened everybody to the ground, which leads the audience to clap the dancers, who try to counteract it. But just with the modern dance the use of the metakinetic become artistic.

Germans understood its importance, in fact they define their dance as "expressionist", that is a sort of dance that expresses movement. Given the close relationship among movement, personal experience, temperament, mental and emotional stock, it is possible to teach to everybody to do exactly the same movement. The best dance teacher educate pupils to find their own way of moving. Rudolf von Laban, the German theoretician, has divided human people in three categories, according to the type of their movement, as well as singers are divided in the categories of soprano, tenor, etc.

According to the metakinetic, he has made some important discover thanks to the research in the physiological and psychological fields. He has discovered that tall and thin persons move nearly in the same way. Instead, persons who are short and stocky, "short dancer", move in another way. "Medium dancers" are in the middle. They do not move in a certain way because they are of a certain height, either they are not of a certain height because they move in a certain way. These, height and way of moving, are both the results of intellectual, personal and psychological characteristics.

All these considerations are a validation of the metaphysics' theory asserting that kinetic and metakinetic are two sides of the same background reality.

\subsubsection{Natural and Artistic}

We do not have to put at the same level artistic and natural movement, but we have to distinguish between the movement of the daily routine and the movement built and created by a creative willingness. If the movement permits us to obtain expressive art, we have to wonder which kind of art creates movement. It cannot be made up just of a body that move rhythmically, because the movement occurs trough a "medium" that is not the body, even if it is tightly linked to the body itself. The body is just a part of the oeuvre. The other part is the space: because it is 
obvious that body and space together permit movement. If we consider just the body, we cannot imagine moving differently from the stylization of the natural daily gesture. The daily gesture is always a reflected movement, functional or emotional, but its mainly characteristic is to be involuntary and that it has not a conscious spatial trend. The gesture occurs in the space, but it is not formed on the basis of space. A movement is artistic when the gesture develops harmonically with the spatial rules and with the chances of body physic movements. So, a gesture can be defined as artistic. Creative Movement (and Dance) space is not either just a physic space or the real space of human's daily routine, but it includes even the dimension of the space of the time. It is a three-dimensional space (length, width, and height) besides the time, without the time the movement is not actual. But the most influent element on the actor-dancer is the space of energy. Each gesture is strain to move away from the centre of the body and to return to it, it is radiation or control of energy. Energy, in this case, manifests itself in three fundamental forms: fluent, tensed and pushed, like rush, strain and impulse.

\subsubsection{Physic Exercises}

The following exercises are described in JERZY GROTWSKI, Towards a Poor Theatre, Simon and Shoster, 1968.

\section{Warming-up exercises}

1) Rhythmically walking while the arms and hands rotate.

2) Running on tiptoe. The body must feel a sensation of fluidity, flight, weightlessness. The impulse for the run comes from the shoulders.

3) Walk with knees bent, hands on hips.

4) Walk with knees bent, gripping the ankles.

5) Walk with the knees slightly bent, the hands touching the out-side edges of the feet.

6) Walk with the knees slightly bent, holding the toes with one's fingers.

7) Walk with the legs stretched and rigid as though they were being pulled by imaginary strings held by the hands (the arms stretched out in front).

8) Starting in a curled up position, take short jumps forward, always landing in the original curled up position, with the hands besides the feet.

Note: Even during these warming-up exercises the actor must justify every detail of this training with a precise image, whether real or imaginary. The exercise is correctly executed only if the body does not oppose any resistance during the realization of the image in question. The body should therefore appear weightless as malleable as plasticine to the impulses, as hard as steel when acting as a support, capable even of conquering the law of gravity.

\section{Exercises to loosen up the muscles and the vertebral column}

- "The cat": This exercise is based on the observation of a cat as it awakes and stretches itself. The subject lies stretched out face downwards, completely relaxed. The legs are apart and the arms at right angles to the body, palms towards the floor. The "cat" wakes up and draws the hands in towards the chest, keeping the elbows upwards, so that the pals of the hands form a basis for support. The hips are raised, while the legs "walk" on tiptoe towards the hands. Raise and stretch the left leg sideways, at the same time, lifting and stretching the head. Replace the left leg on the ground, supported by the tips of the toes. Repeat the same movements with the right leg, the head still stretching upwards. Stretch the spine, placing the centre of gravity first in the centre of the spine, and then higher up towards the nape of the neck. Then turn over and fall onto the back, relaxing.

Handstand with the feet together against the wall. The legs slowly open as wide as possible.

Resting position. Squatting with the head dropped forward and the arms dangling between the knees.

Upright position, with the legs together and straight. Flex the trunk towards the ground until the head touches the knees. Keeping the legs together, jump onto a chair. The impulse for the jump does not come from the legs but from the trunk. Total or partial splits.

Starting from an upright position, bend the body backwards to a "bridge" until the hands touch the ground behind.

Lying position stretched out on one's back. Roll the whole body vigorously to left and right.

From a kneeling position, bend the body backwards into a "bridge" position until the head touches the ground.

Note: It is equally incorrect to perform this series of exercises in an inanimate way. The exercise serves the research. It is not merely automatic repetition or a form of muscular massage. For example, during the exercises one 
investigates the body's centre of gravity, the mechanism for the contraction and relation of the muscles, the function of the spine in the various violent movements, analysing any complicated developments and relating them to the repertory of every single joint and muscles. All this is individual and is the result of continual and total research. Only the exercises which "investigate" involve the entire organism of the actor and mobiles his hidden resources. The exercises which "repeat" give inferior results.

\section{Flight}

Squatting on the heels in a curled up position, hop and sway like a bird ready to take flight. The hands help the movement as wings.

Still hopping, raise yourself into an upright position, while the hands flap like wings in an effort to lift the body.

Take off in flight with successive forward movements somewhat similar to the action of swimming; while the body is carrying out these swimming movements, there is only one point of contact with the ground (e. g. the ball of one foot). Take swift leaps forward, still on the ball of one foot. Another method is as follows: recall to mind the flying sensation one experiences in dreams and spontaneously recreate this form of flight.

Land like a bird.

Note: Combine these exercises with others based on falls, somersaults, leaps, etc. One should aim at achieving a long flying-leap which begins like a bird taking off and finishes as it comes to land.

\section{Leaps and somersaults}

Forward somersault using hands as supports.

a)Forward somersault, helping oneself up with one's hands; b) Forward somersault, without the use of the hands; c) Forward somersault, finishing up on one leg; d) Forward somersault with the hands behind the back; e) Forward somersault with one shoulder touching the ground for support.

Backward somersaults. "Tiger" spring (diving forward). With or without a preparatory run, arms outstretched, spring over an obstacle into a somersault, landing on one shoulder. Get up in the same movement. "Tiger" spring followed immediately by a backward somersault. Somersault with the body rigid like a marionette, yet as though there were a roping inside it.

Note: Throughout these exercises, apart from the "research" factor and study of one's own organism, there is also an element of rhythm and dance. The exercises - especially in the case of the "battle" variations - are performed to the beat of a drum, tambourine or other object, so that both the performer of the exercise and he who beats out the rhythm improvise and provide a reciprocal stimulus. In the "battle" sequences, the physical reactions are accompanied by spontaneous and inarticulate cries. The actor must justify al these semi-acrobatic exercises with personal motivations, stressing the composition of the initial and finale phases of the exercise.

\section{Foot exercises}

Lie on the floor with the legs slightly raised. Do the following movements with the feet:

a) Bending and stretching of the ankles, forwards and backwards; b) bending and stretching of the ankles, sideways; c) Rotatory movements of the feet.

- Standing position: a) bend at the knees with arms outstretched, keeping the feet flat on the floor in the same spot all the time; b) walk on the edges of the feet; c) walk pigeon-toed (i. e. with toes turned inwards, heels well apart) on tiptoe; d) walk on the heels; e) bend the toes in towards the sole of the foot and then upwards in the opposite direction; f) pick up small objects with the toes (a box of matches, a pencil, etc...)

\subsubsection{Plastic Exercises}

\section{Elementary exercises}

Walk rhythmically with arms stretched out to the side. Rotate the shoulders and arms, pushing the elbows back as far as possible. The hands rotate in the opposite direction to the shoulders and arms. The whole body reinforces these movements and, while rotating, the shoulders are raised absorbing the neck. Imagine you are a dolphin. Gradually increase the rhythm of the rotations, let the body grow in height, walking on the tips of toes. "Tug-of-war". An imaginary rope is stretched in front of you and it is to be used to help you advance. It is not the arms and hands which pull the body, but the trunk which moves towards the hands. Heave yourself forward until the leg behind touches the ground with the knee. The body movements must be sharp and strong like the bows of a ship cleaving a huge wave. 
Make a jump forward on the tips of the toes, bending the knees on landing. Return to the standing position with an elastic and energetic movement and repeat the same jump forward, still on tiptoe, followed by the knee-bend. The impulse comes from the thighs which act as the spring regulating the bending phase and the jump which follows. The arms are stretched out to the side and while one palm caresses, the other repels. One must have a sensation of being extremely light, soft and elastic like foam rubber.

Walking rhythmically. The first step is a normal one; on the second, bend at the knees until the buttocks touch the heels, keeping the trunk erect. Rise to a standing position in the same rhythm and repeat the same sequence of a normal step alternated with a knee-bend. Improvisation with the hands. Touch, skim, feel, caress various objects, materials, textures. The entire body expresses these tactile sensations. Unexpected movements. Make a movement as, for instance, the rotation of both arms. This movement begins in one direction, which, after a few seconds, proves to be the wrong one: that is to say, the opposite to that intended. The direction is then changed, after a brief moment of immobility. The beginning of the movement must always be emphasized and the suddenly change - after a moment of immobility - to the correct movement. Another example: start walking slowly, as if with difficulty ad effort. Suddenly, after standing still for a moment, start to run very lightly and gracefully.

Note. These exercises are based on Dalcroze (Oliva, 2010: pp. 111-141) and other classical European methods. Their fundamental principle is the study of opposite vectors. Particularly important is the study of vectors of opposite movements (e. g. the hand makes circular movements in one direction, the elbow in the opposite direction) and contrasting images (e. g. the hands accept, while the legs reject). In this way each exercise is subordinated to "research" and to the study of one's own means of expression, of their resistances and their common centres in the organism.

\section{Composition exercises}

The blossoming and withering of the body. Walk rhythmically. As in a plant, the sap rises, starting from the feet and spreading upwards through the entire body, reaching the arms which burst into blossom as indeed does the whole body. In the second phase, the limbs-branches wither and die one by one. Finish the exercise on the same rhythmic step with which it began.

- Animal image. This does not consist in the literal and realistic imitation of a four-legged animal. One does not "act" an animal but attacks one's subconscious, creating an animal figure whose particular character expresses an aspect of the human condition. One must start from as association. Which animal does associate with pity, cunning, wisdom? The association must not be banal, stereotyped - the lion representative of strength, the wolf of cunning, etc. It is also important to determine the animal's centre of vitality (the muzzle of the dog, the spine cord of the cat, the belly for the cow, etc.).

- The flower. The feet are the roots, the body is the stem, and the hands represent the corolla.

The whole body lives, trembles, vibrates with the imperious process of bursting into flower, guides by one's associations. Give "the flower" a logical signification, one which is at the same time sad, tragic and dangerous. "The flower" is separate from the process which created it and that part of it expressed through the hands is used as a rhetorical gesture in a dialogue.

The study of different types of gait. Type of gait determined by age, transferring the centre of the movement to the different parts of the body. In infancy, the legs ate the centre of the movement; in the adolescent period, the shoulders; in the manhood, the trunk; in maturity, the head; in old age, the legs again. Observe the changes in the vital rhythm. For the adolescent the world is slow in relation to his movements, whereas for the old mad the world moves fast in relation to hi,- These are, of course, only two of the possible keys for interpretation.

Choose an emotional impulse (such as crying) and transfer it to a particular part of the body - a foot, for example which then has to give it expression. A concrete example of this is Eleonora Duse who, without using her face or arms, "kissed" with her whole body. Express two contrasting impulses with two different parts of the body: the hands laugh while the feet cry.

Note. These exercises have been adapted according to the process of the formation of gesticulatory ideograms as in ancient and medieval theatre in Europe as well as African and oriental theatre. It is not, however, a question of seeking fixed ideograms as, for example, in the Peking Opera in which, in order to portray a particular flower, the actor makes a specific and unchangeable gesture inherited from centuries of tradition. New ideograms must constantly be sought and their composition appears immediate and spontaneous. The starting point for such gesticulatory forms is the stimulation of one's own imagination and the discovery in oneself of primitive human reactions. The final result is a living form possessing its own logic. These exercises in composition present unlimited 
possibilities. Here only a few of those which are suitable for further development will be dealted with.

\subsubsection{Exercises of the Facial Mask}

These exercises are based on various suggestions made by Delsarte, particularly his division of each facial reaction into introversive and extroversive impulses. Every reaction can, in fact, be included in one of the following categories:

Movement creating contact with external world (extroversive).

Movement which tends to draw attention from the external world in order to concentrate it on the subject (introversive).

Intermediate or neutral stages.

A close examination of the mechanism of these three types of reaction is very useful for the composition of a role. On the basis of these three types of reaction, Delsarte supplies a detailed and exact analysis of the human body's reactions and even those of parts of the body such as the eyebrows, eyelids, eyelashes, lips, etc. Delsarte's interpretation of these three types of reactions is not, however acceptable since it is bound to nineteenth century theatrical conventions. A purely personal interpretation must be made.

The reaction of the face corresponds closely with the reactions of the entire body. This does not, however, exempt the actor from executing facial exercises. In this respect, in addition to Delsarte's prescriptions, the type of training for the facial musculature used by the actor from the classical Indian theatre, Kathakali, is appropriate and useful. This training aims to control every muscles of the face, thus transcending stereotyped mimicry. It involves a consciousness and use of every single one of the actor's facial muscles. It is very important to be able to set in motion simultaneously. But at different rhythm, the various muscles of the faces. For example, make the eyebrows quiver very fast while the cheek muscles tremble slowly, or the left side of the face react vivaciously while the right side is sluggish.

All the exercise described in this chapter must be performed without interruption, without pause for rest or private reactions. Even short rests must be incorporated as an integral part of the exercises, whose aim is not a muscular development or physical perfectionism, but a process of research leading to the annihilation of one's body resistances.

\subsubsection{The Movement}

When you are on the stage, every movement should meet a necessity criterion. If you do not need to move, you can stand still. The actor should resist to the temptation to "move the action", because it can be useless and even divert attention from the centre of the narration. A movement from right to left can be important and even narrative, but if it is neither important nor narrative, stand still.

You can:

a) To move from a point to another (getting closer, go further).

b) To do a gesture.

The movements are linked to the creation of the role. The gesture is added to the heart, the spirit and the brain of the character, so it is important that the actor is aware of his physic skills. The inner need to "live" lines is the same that permits the movements on the stage. The movement style (naturalistic, anti-naturalistic) is tightly linked to the acting style and to the global idea of the performance.

We can assert that actor's body expression is the frame of his acting. A physical training can be useful to try out our strengths, and to develop our skill. Some characters require a good gymnastic preparation (for example some characters of the Comedy of Art or some Shakespearian characters). Every actor can train his body, even in a common fitness centre. This kind of training can be useful to develop the physic and the concentration too. An actor can train himself even following dance courses, being aware to be an actor and not a dancer. Dance courses should be hold by an expert.

Actually, a lot of actors, even famous actors, have never really taken care of their body. Anyway, they have taken care of every little detail requested by their art, movements and gestures too.

The actor creates his character even just walking on the stage. The way of walking from one point of the stage to another produces the aesthetic characteristic of that role. Actors copy reality and have to keep a sort of balance between themselves and the characters. So, we should observe the others in their daily routine. It fact, it could be a 
good result if we succeed in interpretation other's way of walking. Actors have to take care to not exaggerate repeating other's movements. In fact every actor should transform an observed movement into an own movement. It cannot be just an imitation. An actor should be able to use the more helpful gestures and movements to communicate. Be careful: a lot of pupils cannot walk on the stage and, above all, cannot walk in their daily life. An actor, who wants to play a lot of different roles, should have a good base on which build different characters. The base is his "normal" way of walking. If the actor walks keeping legs wide apart or too close, or if he has feet wide apart or converging; if he takes arms stuck to the body or rolls them around; if he walks jumping or dragging his feet he characterizes his way of walking too much, in fact:

a) He could not be able to "normally" move;

b) He could not research freely others interesting characterisations.

Exercises: walks

Exercise 1: Observe you while you are walking. Be careful to not "playing" the walk and try to be spontaneous. Try to understand your type of walk.

Exercise 2: After the observation try to modify those elements you think are not "normal". If you think you are "normal", study the elements of your regularity. Catalogue them in your mind (how your steps are, how many steps you do. Flexibility of your legs. Position of arms, of trunk, of shoulders, and so on).

Exercise 3: Think to a friend or somebody that has aroused your curiosity because walks in a very particular way (a neighbour, a teacher, a friend). Try to transfer some of his physical characteristics on you, without trying to imitate him but even considering his psychological characteristics.

So, you do not have to copy or to imitate, but you have to create a character. Just try to walk like this character should walk.

\section{Trunk position: exercises}

Every movement, on the stage, must be linked to the "playing gaze": the eyes are the meeting point between the words and the position. For example, imagine an actor's gaze during a love scene. His words should be united to a delicate and affectionate physical position.

Exercise 1: Stand at attention and walk from a wall of the room the opposite one. Do short steps and keep the heel of the left foot on the same line of the big toe of the right foot, and so on. Balance the movement of the arms, moving them to and fro. The trunk and the head are erect; the eyes look proudly straight in front of you. When you get the opposite wall, turnabout. Walk doing longer steps, always keeping feet on the same line. The trunk and the shoulders are flabby and sloping. The head is bended towards the ground, the gaze is fearful. When you arrive at the first wall stop for a while. Keep the position, bending knees and feeling uneasy. Turn slow about, and stand proudly upright again. Cross again the room. You have to pay attention to the right about turn movement, to control muscles and to manage to communicate your actual intention.

\section{Neck stretching exercises}

The neck and its mobility are very important to act. The neck permit to move the head, and, consequently, the look that allows actors to communicate with the viewers. For example, even the velocity of the head movement underlines actor's intentions. If you move your head a little bit ahead, you can communicate you need help. If you move it a little bit backwards, you can communicate you want to go away. These are just some examples that should be linked to the whole interpretation to really have these meanings. Anyway, an actor should be able to move his body as he desires, to face every kind of situation. Exercise 1: Leaning your hand against a wall, extending your arms. The body is a little bit bended ahead:

a) Look in front of you;

b) Gently turn your head to the left, looking over your left shoulder;

c) Return to starting position;

d) Gently turn your head to the right, looking over your right shoulder;

e) Return to starting position;

f) Repeat point b) faster;

g) Repeat the sequence faster and faster. 
Exercise 2: Repeat the exercise 1 but without keeping hands against the wall. Repeat the exercise 1: having your hand on your hips; keeping legs wide apart; on your knees; sitting with cross legged; sitting with legs stretched ahead and with palms on the ground.

\section{Legs: exercises}

An actor should be able to control his legs, when he stands still and when he walks. This control is related not only to the physical exercise, but even to a good concentration skill.

Exercise 1:

a) Lay on the ground, keeping the legs united;

b) Raise legs making a right angle;

c) Bend your knees as much as possible;

d) Stretch right leg to ground, keeping the left one bended;

e) Stretch even left leg to the ground;

f) Repeat the exercise more times;

g) Repeat b)

h) Repeat c)

i) Do a sort of 'pedaling' motion laying on the ground

Exercise 2: Lie face down, keeping your hand under your forehead. Relax, thinking over the previous exercise. Then, keeping hands under the forehead arch your back, making your knees slide towards your belly. Repeat the exercise more times.

\section{Upper limbs}

Usually upper limbs movements are useful to comment on actor's words. A Italian person moves his upper limbs differently respect a English one. An actor should move his arms and hands like he prefers, even if he can study a particular form of expression in relation to every particular role. Anyway, we do not think that an actor should keep his arms still, because we think that the gesture of the human-actor is narrative when it is automatic, as well as his words are narrative when they are spontaneous.

Actors do not have to use too many daily gestures that is those gestures that mime a communication. In fact, this kind of gestures cannot be universally understood.

We do not propose exercises to train upper limbs, because we think we train them enough through our daily movements. Anyway, we think it can be helpful to observe carefully gestures to catalogue them.

The gesture: exercises

The gestural activity on the stage should underline actors' words, and not to be opposite of the narration. Usually, a gesture should be wide, to allow communication even with furthest viewers. Gestures should be visible and complete even when actors stand one close to other (for example, during love or fight scene). We can underline that gestures are explicit $\mathrm{n}$ daily life too. We always prefer an actor who does not do any gestures, rather than an actor who do weak gestures. Sometimes, some actors seem to not know how to move their hands. Actually, if the actor pays attention to his interpretation, hands will become a part of the role. If an actor thinks his hands are a problem, probably he is not really gotten inside his part.

Exercise 1: Prepare a tea, without using any object. Turn up the fire, put the teapot on it. Wait for the water boils. Pour the water into a cup and put a teabag into it. Put into it some sugar, stir it. Sip the tea tasting it.

Exercise 2: You have to move remembering actual gestures, and you have to be sure that you are communicating with the audience. The actor must "catalogue" the objects just thanks to his mind. Actor's hands must feel objects.

Exercise 3: Put in a non-existence pot twelve red roses, seven sword lilies, and five daisies. You have to take care, because roses have prickles, the sword lilies are taller than roses and daisies are larger than roses. The tap is far. The pot is made of glass.

Exercise 4: Tear a big sheet of a newspaper paying attention. Tear it slowly and try to make equal parts. Tear each part until you can make a piece of paper as big as half hand palm. The gesture should have a meaning. When you have your bundle, throw it all around. Then pick up each little piece of paper. 


\subsection{The Laboratory Acting Voice}

The characteristics of acting voice (Teodoro Amedura, 2011: pp. 84-91) The voice of the persons who speak in public should be powerful. It should be powerful when the volume is low or high, when you speak loud and when you speak almost blowing (like when you speak lo)

The voice is a medium of communication, and each person should be able to use it according to the expressive necessity. The high volume should not be a scream, but a great phonic presence and the low volume (blown words or not) should be anyway perceptible. The voice must be stimulated, reinforced, but not changed; it is strictly linked to the natural characteristics of each person.

The voice should be trained to give to the phonic emission an effective rationality and a great precision. So every person can get the fundamental knowledge of the vocal media and he can understand how to use them.

The elements of the voice are breathing, rhythm, intensity, tone, time as length, timbre, volume.

The speed and the tonic accent of the words give the rhythm.

The intensity is the strength and the vigor of the expression.

The tone is the height of the voice (that can be by chest, by head or by belly).

The time/length is the duration of the exposition of a word, a sentence, a line.

The timbre (or tone color) is the particular characteristic of the voice. Every person has her own timbre. The volume is the quantity of the emitted voice.

\section{The importance of respiration}

The control of respiration must anticipate the study of a voice. The respiration controls the emission of every kind of phoneme. For every person, the best kind of breathing is the spontaneous one. We can say that there are two type of natural breathing.

Upper (chest breathing),

Lower (abdominal breathing).

A good respiration to act is composed by the two different kinds mixed together.

"Over-getting, under-getting". The upper breathing allows producing the high tones and the lower breathing allows producing deep tones.

To control the correctness of your respiration lay flat on your back. Place one hand on your chest and one hand on your belly. Then breathe in deeply and check to feel the hand placed on your belly raises first. Then the hand placed on your chest should rise too.

The respiration should be linked to the speech and to the requirements of the emission.

\section{Breathing exercises}

Upright position, arms stretched ahead slightly apart; clench your fists.

a) Inhale: the air gets in slowly, but without any interruptions or jerks. Breathe in with your nose or with your mouth, as you prefer.

b) Keep the breath for five seconds.

c) Exhale: exhale slowly keeping the mouth half-closed, until feeling a sort of an emptying effect.

Upright position, keeping your hands behind your back. The right hand holds the left wrist.

Repeat the first exercise.

Relaxation exercise:

Repeat the a) letter of the first exercise.

Repeat the b) letter of the first exercise.

Exhale emitting the sound "pf", blowing and keeping the mouth half-closed.

Vocalization Exercises

These exercises should be performed with a pretty high volume. It is important to open the larynx to perform a very good vocal emission (that is, you have to clear your throat). 
Standing, wide apart legs slightly. To inhale through the nose. Break. To expire sending forth the sounds (These exercises are referred to the Italian sounds): "a, e, i, o, u"

Variations of tone with the sound 'a'

$\begin{array}{ll}\text { High } & \rightarrow \text { aaaaaaa } \\ \text { Middle } & \rightarrow \text { aaaaaaaa } \\ \text { Low } & \rightarrow \text { aaaaaaaa }\end{array}$

Variations of volume with the sound 'a'

\begin{tabular}{|c|c|c|}
\hline High & $\rightarrow$ & $A A A A A$ \\
\hline Middle & & AAAAA \\
\hline Low & $\rightarrow$ & AAAAAA \\
\hline
\end{tabular}

Repeat with other sounds.

Exercises of strengthening of the voice

Standing. To inhale. Break. To expire sending forth a sound in light way and increasing the volume up to the maximum one and decreasing up to the whispered one. To vary only the volume and not the tone of the voice.

Standing. To inhale. Break. To expire sending forth a sound departing from the highest tone and gradually to reach the lowest tone. To vary only the tone and not the volume of the voice.

\section{Words exercises}

Choose a sentence composed by 6 words. Divides it into syllables and pronounce them one by one speaking loud.

Pronounce the same sentence in a strange way, deforming it, using face muscles and even the body (pulling a wry face, stretching arms and legs, rolling about on the floor, beating fists on the wall, shaking the bottom, getting angry, getting relaxed. Do not scream!)

Take care of your speeches during your daily routine. Try to speak always correctly,

Try to speak taking care of pronouncing every syllable of each words, above all the last one of every word.

To practice in the song. The song is an useful exercise to learn to use the voice because it is a natural activity. The song trains in automatic way to dose the quantity of breath that needs for pronouncing the single strophes.

Repeat many times the exercise.

\section{Third Part: A Project}

In the sensitive period of the growth, it is extremely useful that children and teenagers receive many stimuli to help them to understand the different aspects of reality, and to discover their resources and their limits. Furthermore, it is essential that they will relate with adults able to give satisfactory answers, without the claim to decide for them what to do, but simply able to offer an educational proposal that would give a meaning of life. In particular it is useful that this educational need is upheld and carried out within the School, since these students are inserted in a path that will lead to the training of their personal identity and everything they face is a continuous discovery. It is important to promote in school prevention through educational tools aiming at the development of creative skills, abilities present in every human. An efficient tool to stimulate the expression of personal creativity, of self-discovery and of interaction cooperative with others is the theatrical experience, more precisely the theatre laboratory, conceived in relation to the real needs, interests and skills of kids. The laboratory is in fact a vehicle through which they can search and discover their own identity (that is linked not only to the body), not only at the individual level, but also at the group level.

Then, teachers have to active participate, working with the Educator to Theatricality.

\subsection{Recipients}

A project is organized by age classes. Activities can be developed in the School in collaboration with teachers or in educational centers in collaboration with educators.

- Children: three, four, five years old

Laboratory of expressiveness and dramatization: "Gioco Drammatico" (Dramatic play: Oliva, 2010b). 
Organization

The duration of the laboratory is 12 hours for group.

Groups of 10 children for educator.

Each appointment lasts about 40-45 minutes.

A meeting to week: number 1.

- Children: six, seven, eight years old

Laboratory of expressiveness and dramatization: Il "gioco drammatico" (Dramatic play: Oliva, 2010b).

Organization

The duration of the laboratory is 15 hours for group.

Groups of 15 children for educator.

Each appointment lasts about 1 hour.

A meeting to week: number 1 .

- Children: nine, ten, eleven years old

Laboratory of expressiveness and dramatization.

Organization

The duration of the laboratory is 15-20 hours for group.

Groups of 15-20 children for educator.

Each appointment lasts about 1 hours and half.

A meeting to week: number 1 .

- Teenagers: eleven, twelve, thirteen years old

Laboratory of expressiveness and dramatization: education to the creativeness

Organization

The duration of the laboratory is 20-25 hours per class.

Each appointment lasts about 1 hour and half -2 hours

A meeting to week: number 1 .

- Teenagers: fourteen, fifteen, sixteen, seventeen, eighteen years old

Laboratory of expressiveness and dramatization: education to the creativeness

Organization

The duration of the laboratory is 30-35 hours for group.

Each appointment lasts about 2 hours

A meeting to week: number 1 .

- Adult

Laboratory of expressiveness and dramatization: education to the creativeness

Organization

The duration of the laboratory is 40-60 hours for group.

Each appointment lasts about 2 hours

A meeting to week: number 1 .

\subsection{Finally}

Encourage the psycho-physical and social wellness of the children and teenagers in relation to its age through the theatrical culture and, in particular, through the laboratory.

3.3 Objectives

Discovery and development of creative potentialities and of socialization; enhancement of imagination and mimicry 
expression; self-awareness; expression through the gesture, the voice, the colors, the sound, the story-telling, the movement.

\subsection{Contents}

- Non-verbal language: creative movement:

- Awareness of the body and its expressive possibilities (breathing, coordination and dissociation, balance, contraction and relaxation, theatrical space, equilibrium of the stage, Greek choir, etc.).

- Education and control of voice and muscles.

- Verbal and non-verbal communication.

- Individual and collective improvisation with and without music.

- Composition of sequences in the group.

- Use of space in each dimension.

- Telling a story with your body.

- History, action - process, composition.

- Construction and use of the neutral mask.

- Verbal language: the theatrical reading:

- Technique of voice and phonetic rules.

- Breathing exercises for the proper use of the diaphragm.

- Labial gymnastics and vocal exercises for good articulation.

- Phonetic rules.

- Exercises of modulation of the voice.

- Use of physiological resonators.

- Colours of words.

- The space: handling of material and creativity:

- The space of representation and the stage space.

- Space: Movement and performance space.

- The use of different scenic materials and articles.

- The handling of the materials.

- Planning and construction of sets and costumes.

- The relationship between music and the scene.

- Detection of sounds and noises and sound effects creation.

- The play: (children who can write; indicatively children above the age of six)

- The text: reading, analysis and interpretation.

- The relationship between dramatic text and narrative text.

- The specificity of the play: exercises.

- Analysis of some plays.

- The dramaturgical model.

\subsection{Method}

Every appointment should be fun and educational ad every child or teenager will be available to work with different techniques and materials to stimulate his fantasy. Each topic will be introduced by explicit references to the History of Theater. The moments of this route are articulated to experiment verbal and non-verbal languages, in particular through the use of the "story-telling". Laboratory is a safe environment, without any judgment, which allows the participants to release their feelings and emotions, procured through the experience of dramatic narrative the gratifications they need and to meet other personalities in a fun and deep collaboration. Story-telling is very 
important for every human being. Furthermore, even hear the stories of others is important: these stories are mirrors in which each individual sees aspects of himself. Often, however, this information remains at an unconsciousness level, to which a boy can access only in specific situations, for example, during the theater laboratory, where the student is stimulated to create and tell stories.

At the end of each appointment there is a moment of feedback, that is dedicated to the verbalization. This promotes the externalization of opinions and experiences favoring a critical observation of the experience and improving the ability of sharing thoughts in a context that does not wants to be judgmental and in which are taken into consideration the activities and not the personal elements of each subject; it will be accomplished by using age-appropriate tools and considering the ability of recipients. The plan consider the process experienced by every teenager the most important phase of the laboratory, and it will lead to the construction of a creative project (a performance), which will be the visible result of the whole process.

\subsection{Check}

There are some intermediate and final check which are useful to orient the work, through a series of individual and collective tests. They are useful to evaluate what changes have occurred in each student and in the relationship between the members of the group according to the offered stimuli, to the contents of the course and understanding the degree of interest of every different modules. Therefore, this check should be realized by the theatricality educator who leads the laboratory; he will tend to widen the check in collaboration with teachers who are participating in the activity. There are:

- Identification by the theatricality of the educator of sensitive teachers who can accept to plan activities in collaboration;

- Planning moments of verbalization to allow an exchange between the participants about the activities carried out, the degree of understanding and experiences related to the proposed stimuli;

- Motivate the operational proposals and their goal for help students to achieve a level of self-assessment;

- Assume some moments when the spectators can become part of the scene, such as answering or being called into question;

- Educators and teachers should give just a superficial information about the content and the development of thematic regarding the performance they will see to be allowed to understand the final product;

- Prepare illustrated flash card that synthesize the experience to prepare an exhibition as introduction to the final performance.

\subsection{Theatrical Pedagogy: A New Pedagogical Practice}

In reference to the chance to find a new way of education, we have tracked down and discovered a new road illuminated by expressive arts. When you understand how the reference to beauty is inherent in human being, and how he need to translate, explain and show himself through the artistic language, we understand that art can be a privileged way to discover a meaning of life. Art therefore has transcended the mere definition of product with which for too long has been linked, to be considered in a totally different logic: a logic focuses on the process, that allows every human to discover himself, in relation to his Ego and to others.

This has been confirmed by the specific and concrete project, result of a reflection that invoked the educational action of planning in reference to the expressive arts. Expressive arts can be considered as innovative tools to support the human being in his endless existential quest. If we consider them a vehicle, we can say that they represent the preferred way to reach the inner Ego of the human and give breath to everything that otherwise would remain intimately silent. Art offers the great privilege of understanding the human being in his totality and uniqueness, because it reflects the unity of its essential elements (which are body, soul and intellect). It can be stated that in art and thanks to art, man can manifest itself fully and truthfully. Moreover, thanks to the innovative work made by some great figures of the Twentieth century like Jerzy Grotowski, we know that there is a primary need to focus on our body and that is necessary to "listen" to it to fully consider their own experience. Without an awareness of the corporeal being, in fact, the man would be incomplete and would never be able to reach the meaning of his existence.

Through this work, moreover, it was possible to conceive an education that goes beyond the simple everyday life, to rediscover it under a new aspect thanks to art, which allows users to review their daily actions giving a deeper meaning. In particular, it has been demonstrated how a theatre laboratory, offers a training course that allows persons to rediscover their Ego. This is necessary for every human being because it allows him to put himself on the line, to build more solid convictions; it is a journey that leads him to get lost, but only to find himself stronger, with a deeper 
awareness about his personality, his relationship with others and with the surrounding environment. Moreover, with a profounder consciousness of his limitations and his potentialities, combined with a more conscious creative feeling. Since every man is part of a continuous movement (from a physical and existential point of view), it seems essential to propose an experience that will bring every man to fully enjoy the creative fluidity in which he is naturally inserted, and we can name it creative movement.

Refer and deepen this perspective is really important in the field of education, because it leads the human being to come into contact with his Ego and with the others, sharing everything: body, soul and intellect. If you share the most intimate part of yourself with the other you can create a constructive and educative dialogue. This is the actual challenge of an educator, who wants to plan using expressive arts: achieving the intimacy of the person to extract its deeper skills, but above all, to ensure that everything can be constructed through an individual path made of sharing.

Expressive arts become a real chance to face the discomfort and the contemporary crisis that the world of education is experiencing. Choosing this way, the educator invests fully on his role and his profession, because he accompanies the person towards himself and to his personal fulfillment, he is a guide to realize a plan of life according to a higher value: the human relationships.

\section{Conclusion: Education to Theatricality: Art As a Training Model}

We have to prepare youth to live in a world of powerful images, words and sounds

UNESCO 1982

The teaching of arts provides an important model for the management of learning processes and training methods. In terms of educational strategies and practices, a learning process based on the artistic model should:

1) Enhance the active and collaborative practice of pupils, directing the process towards a constructivist dynamic. Training would mean to create an environment, a learning community, where people can practice, experience, discuss, learn independently and, at the same time, cooperatively, supported by the teacher that becomes a facilitator of relationships. Regarding the training of the person, this first reflection emphasizes the importance to integrate the education and the action learning that is learning through concrete experiences;

2) Strengthen the idea to work by project; the artist focuses his attention and finalizes his work to an artistic representation: the study and the practice of particular techniques are used to create a creative project. So in the educational field projects can be used to put immediately into practice what has been learned. In addition, projects work, having goals, timelines and resources pushes every person to uses a working method, getting used to cooperation with others;

3) Help pupils to get used to constructive critique; the moment of critique is traditionally linked to the artistic process, because it structures observations and evaluations of the quality of the product and of the creative process. The critique, in the art world, is never linked to the person but it constitutes a fundamental moment of learning for every artist. The external review of a work encourages and motivates the artist to improve his work and his skills. The role of the teacher is not to be an evaluator, expert about the subject, but a coach or a mentor, in essence, a leader of the observation, of critique, of feedback and reinforcement. In the training of a person, the adoption of art as training model can be translated with the diffusion of mentoring and coaching relationships for the development of critical thinking and for the reinforcement and the validation of organizational behaviors;

4) The artist, generally, during his career tends to build its own repertoire of technical methodologies, describing his own process of artistic maturation. Even teachers should adopt and develop an artistic mentality to perform their work at their best. An artist conceives learning as:

- A reciprocal flow, that is two-way, between teacher and pupil. The first one has to create the best environmental and relational conditions to satisfy every different pupil's styles of learning;

- A continuous research for new ideas, materials, stimuli to involve head, heart and hands of people;

- An integrative process of cognitive/quantitative/scientific aspects with emotional/qualitative/artistic traits;

- A set of different activities: play, experimentation and practice, which help to discover new ideas and to develop creativity and a divergent thinking, which verify the assumptions and reinforce every new discovery;

- A virtuous circle in which the perception (watching, observing, analyzing and criticizing) is followed by a research (asking, bringing out, experiencing), by a production (defining goals, planning and implement actions, provide training) and, finally, by a reflection (evaluation, theorization, connection) to the pursuit of quality. 
The expressive arts can be a great tool of involvement training; it can be an attractive vehicle for the transmission of knowledge and for the development of attitudes and skills.

\section{References}

Amedura T. (2011). The Laboratory acting voice, E.te. 1, 84-91, Arona: Editore XY.IT.

Dotti, L. (2006). Storie di Vita in Scena. Il Teatro di Improvvisazione al Servizio del Singolo, del Gruppo, della Comunità. Torino: ANANKE.

Gardella, O. (2007). L'Educatore Professionale. Finalità, Metodologia, Deontologia, Milano: Franco Angeli.

Grotowski, J. (1970). Per un teatro povero, Roma: Bulzoni (1968, Towards a Poor theatre). New York: Simon and Shuster.

Guatterini, M. (2008). L'ABC della danza. La storia, le tecniche, i capolavori, i grandi coreografi della scena moderna e contemporanea. Milano: Mondadori.

Iori V., (editor) Arioli, A., Augelli, A., Bruzzone, D., Carosio, E., Casadio, I., Chiappini, C., et al. (2012). Animare l'educazione. Gioco pittura musica danza teatro cinema parole. Milano: Franco Angeli.

Musaio M. (2007). Pedagogia del bello, suggestioni e percorsi educativi. Milano: Franco Angeli.

Oliva, G. (1998). Il teatro nella scuola. Milano: LED.

Oliva, G. (1999). Il laboratorio teatrale. Milano: LED.

Oliva, G. (2005). Educazione alla teatralità e formazione. Dai fondamenti del movimento creativo alla form-a-zione, Milano: LED.

Oliva, G. (2010a). La musica nella formazione della persona. Arona: Editore XY.IT.

Oliva, G. (2010b). L'Educazione alla Teatralità e il gioco drammatico (Education to Theatricality and dramatic play). Arona: Editore XY.IT

Oliva, G. (2011). The laboratory Dance, exercises and Creative Movement, E.te. 1, 29-46. Arona: Editore XY.IT.

Oliva, G. (2011). Thoughts and Utopia The theatre of the twenty-first century, E.te. 1, 72-82. Arona: Editore XY.IT.

Oliva, G. (2014). Education to Theatricality inside Secondary School, Art and Body. Creative Education, 5, $1758-1775$.

Payne, H. (1997). Danzaterapia e movimento creativo. Trento: Erickson.

Pilotto, S. (2011). The Laboratory and exercises improvisation. Educazione alla Teatralità e.te., 1, 48-64, Arona: Editore XY.IT.

Pitruzzella, S. (2009). Manuale di Teatro Creativo. 200 Tecniche Drammatiche da utilizzare in Terapia. Educazione e teatro Sociale. Milano: Franco Angeli.

Salati, E.M., \& Zappa, C. (2011). La pedagogia della maschera. Educazione alla Teatralità nella scuola, Arona: Editore XY.IT.

Santerini, M., \& Triani, P. (2007). Pedagogia sociale per educatori. Milano: Educatt.

Testa, A. (2005). Storia della danza e del balletto. Roma: Gremese Editore.

Triani, P. (2002). Sulle Tracce del Metodo. Educatore Professionale e Cultura Metodologica. Milano: I.S.U. Università Cattolica. 